devenir Vol. 6, N¹2, ENERO - JUNIO 2019, PP. 155-178 - ESTUDIOS | ISSN 2312-7562 | E-ISSN 2616-4949

UNIVERSIDAD NACIONAL DE INGENIERÍ, LIMA

doi: https://doi.org/10.21754/devenir.v6i12.748

\title{
CAMPUS UNIVERSITARIO Y PATRIMONIO PREHISPÁNICO DIBUJANDO LOS IMAGINARIOS PATRIMONIALES DE LAS HUACAS DE LA UNI ${ }^{[*}$
}

\author{
UNIVERSITY CAMPUS AND PREHISPANIC HERITAGE \\ DRAWING THE HERITAGE IMAGINARIES OF THE UNI HUACAS \\ LUCIANA AUSEJO CALMET ${ }^{[\star *)}$ \\ https://orcid.org/0000-0002-8543-307X \\ kausejoc@uni.pe \\ Universidad Nacional de Ingeniería (Perú) \\ Fecha de recepción: 1 de mayo de 2019 \\ Fecha de aprobación: 19 de agosto de 2019
}

\section{RESUMEN}

El tema del patrimonio prehispánico siempre ha estado ligado con la ciudad y sus relaciones físicas e históricas; sin embargo, las implicancias sociales no se manifiestan abiertamente en textos de carácter científico. El objetivo del presente artículo es comprender la mirada de los sujetos sobre el patrimonio prehispánico que tiene el campus de la Universidad Nacional de Ingeniería. Esta investigación se centra no solo experiencias propias, sino también en las reflexiones sobre los demás campus universitarios que tienen patrimonio prehispánico en Lima, y cuál es el impacto de esto en sus dinámicas sociales, culturales y educativas, y así plantear la posibilidad de incluir al patrimonio como una pieza clave dentro de la nueva visión de universidad y aprendizaje.

\section{PALABRAS CLAVE}

Patrimonio edificado prehispánico; campus universitario; valores patrimoniales

\section{ABSTRACT}

The issue of pre-Hispanic heritage is related to the city and its physical and historical relations, however, the social implications are not openly manifested in scientific texts. The objective of this article is to understand the subjects' view of the pre-Hispanic heritage of the National Engineering University campus. This research focuses not only on their own experiences, but also on reflections on other university campuses that have prehispanic heritage in Lima, and what is the impact of this on their social, cultural and educational dynamics, and thus raise the possibility of including the heritage as a key piece in the new vision of university and learning.

\section{KEYWORDS}

Prehispanic built heritage; university campus; heritage values

\footnotetext{
$\left.{ }^{*}\right)$ El presente artículo es una síntesis del trabajo de investigación desarrollado en el Taller de Investigación de Historia de la Arquitectura, a cargo del Dr. Arq. José Hayakawa Casas, en los ciclos académicos 2018-1 y 2018-2 de la Facultad de Arquitectura, Urbanismo y Artes de la Universidad Nacional de Ingeniería (UNI).

$\left.{ }^{* *}\right)$ Bachiller en Arquitectura por la UNI (2019). Miembro del colectivo Jallalla (2018). Dos veces ponente en eventos de patrimonio cultural de la UNI (2018-2019). Actualmente, se desempeña como asistente de cátedra en el Taller de Investigación de Historia de la Arquitectura I, a cargo del Dr. Arq. José Hayakawa. Desempeña su labor como asistente de arquitectura en Balarq \& Puente Arquitectos.
} 
devenir Vol. 6, N¹2, JULIO-DICIEMBRE 2019, PP. 155-178 - EstudIOS I ISSN 2312-7562 | E-ISSN 2616-4949 UNIVERSIDAD NACIONAL DE INGENIERÍA, LIMA

doi: https:/ / doi.org/10.21754/devenir.v6i12.748

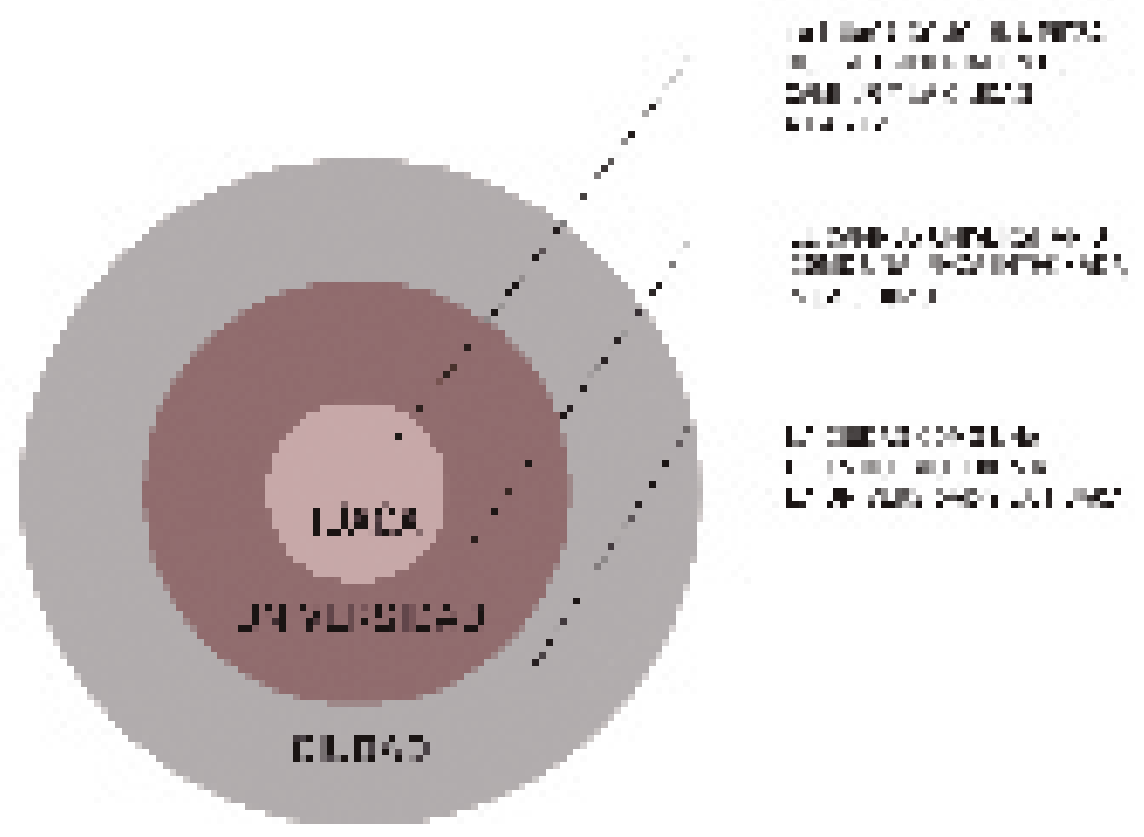

Figura 1. Esquema explicativo de las implicancias del estudio. Elaboración propia, 2019.

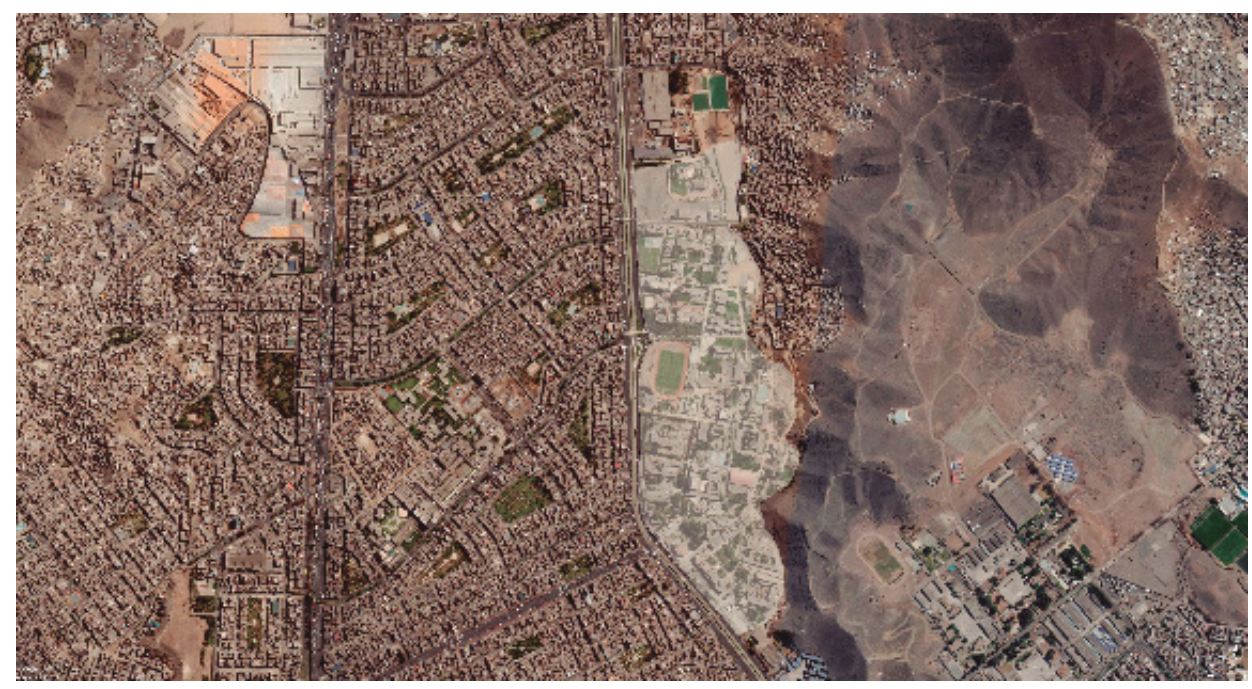

Figura 2. Fotografia aérea del campus UNI en Lima Metropolitana y en su contexto urbano inmediato. Tomado de Google Earth, 2019.

\section{Contexto urbano e histórico}

Como preludio es importante mencionar que, en el extenso territorio peruano, muchos vestigios prehispánicos se encuentran atrapados en barrios y ciudades modernizadas; no obstante, muchas veces, son ignorados. Los planes territoriales de la ciudad de Lima, pocas veces, contemplaron una estrategia de integración de este patrimonio a la ciudad moderna. El avance de la ciudad contemporánea trajo consigo la construcción de muchos campus universitarios, los cuales se emplazaron en la ciudad de Lima y se conocen como ciudades universitarias. 


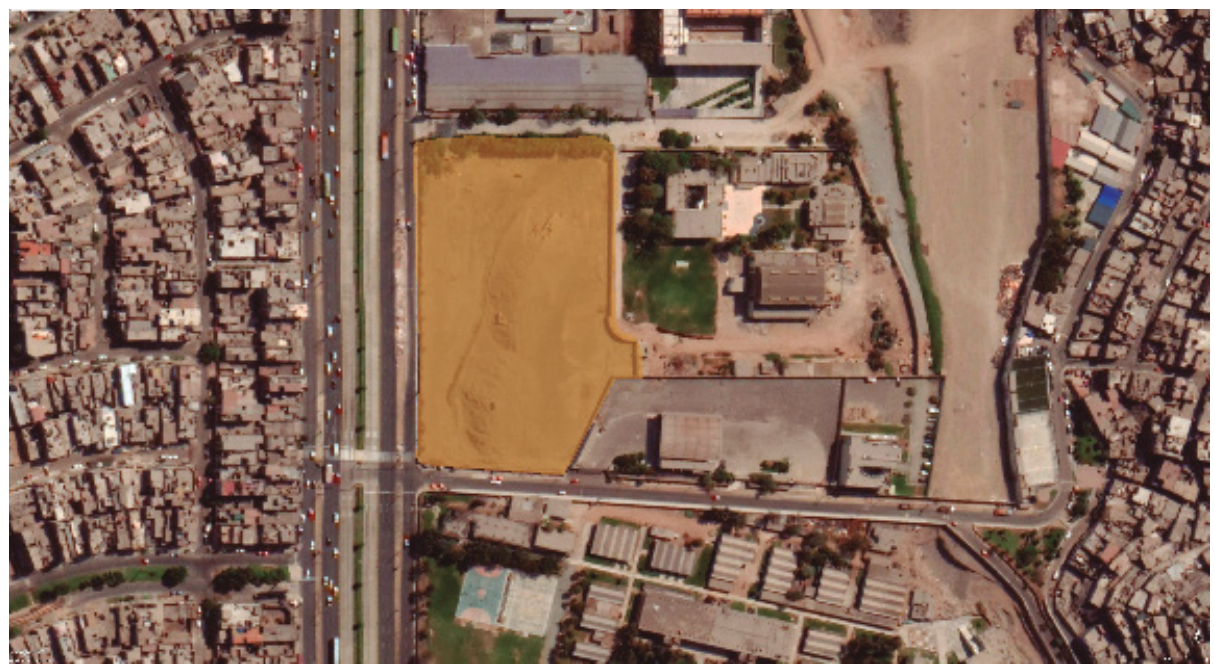

Figura 3. Fotografia aérea de la huaca UNI-Centro Peruano Japonés de Investigaciones Sísmicas y Mitigación de Desastres (Cismid). Tomado de Google Earth, 2019.

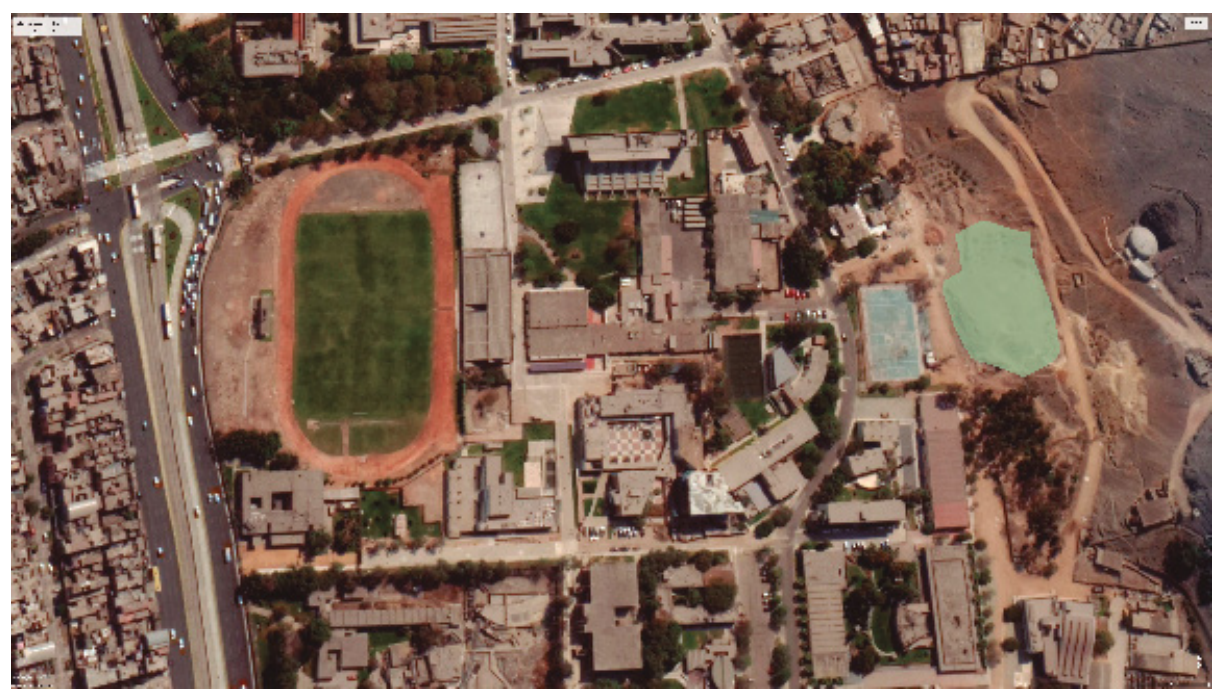

Figura 4. Fotografia aérea de la huaca UNI-Minas 2019. Tomado de Google Earth, 2019.

La Universidad Nacional de Ingeniería (en adelante, la UNI) se ubica en el distrito del Rímac, en la ciudad de Lima, Perú. Se formó como Escuela de Ingenieros del Perú, en 1876, por iniciativa del Estado de la República del Perú. Luego de varios intentos por tener un campus moderno y con la capacidad necesaria para el alumnado, se logró formar el campus universitario, en 1945, con la construcción del Pabellón Central de la UNI. Fue en este terreno llamado Puente Palo, de aproximadamente 37 hectáreas, que se estableció la historia contemporánea de la UNI. Junto con esa ilusión de formar la ciudad universitaria, también se encontraron restos de lo que alguna vez fue un asentamiento prehispánico, perteneciente a la presunta Cultura Collí, en Lima norte.

En el 2017, la UNI comenzó el proceso de reconocimiento y acciones de limpieza de su patrimonio prehispánico a través de un grupo de voluntarios que, posteriormente, se llamó colectivo Jallalla. Este nació en la Universidad y se conforma por un grupo de docentes y alumnos que, de manera voluntaria, realizaron algunas actividades de difusión del patrimonio en el campus. En ese sentido, estas se consideran las primeras acciones tomadas por la institución para revalorar las huacas de la UNI (ver Figura 1, 2, 3 y 4). 
devenir Vol.6, N¹2, JULIO-DICIEMBRE 2019, PP. 155-178 - EstUDIOS | ISSN 2312-7562 | E-ISSN 2616-4949

UNIVERSIDAD NACIONAL DE INGENIERÍA, LIMA

doi: https://doi.org/10.21754/devenir.v6i12.748

\section{Objetivos de la investigación}

El objetivo principal de esta investigación es comprender el valor patrimonial de las huacas de la UNI.

Asimismo, los objetivos específicos son los siguientes:

- Generar la integración del patrimonio prehispánico a los planes institucionales de la Universidad.

- Reconocer la acción patrimonializadora del colectivo Jallalla, para concientizar a la comunidad universitaria sobre las acciones, y así revalorizar las huacas de la UNI.

\section{Metodología: Escuchar a la gente, una estrategia de trabajo}

El diseño metodológico que se utilizó para la captación de datos e información es, principalmente, de carácter cualitativo. Se realizaron una serie de entrevistas semiestructuradas, para poder recopilar información de los principales actores y gestores que participaron en esta investigación. Las principales inquietudes que se generaron al realizar este estudio fueron reconocer el lado humano de la comunidad universitaria de la UNI, y qué tan familiarizados estaban con su patrimonio prehispánico. Esto se logró con la ayuda de actividades dentro del campus, en las que se les preguntaba a los alumnos y profesores qué tanto conocían el patrimonio de la UNI y si estaban familiarizados con él.

La mayoría de estas técnicas tuvieron un componente humanístico. Se registraron las siguientes actividades:

- Actividad Feria Qhatuni 2018-Focus group

- Entrevistas a investigadores y expertos

- Cuestionarios online a la comunidad universitaria

- Captación de información de redes sociales-Twitter

- Captación de información fotográfica en medios masivos de internet

- Producción fotográfica personal

El presente estudio caracteriza el patrimonio prehispánico de la Universidad como hecho físico e histórico según la percepción de la comunidad universitaria. Por ello, debe cumplir con los siguientes aspectos:

- Cualidades de la universidad, como un hecho humano.

- Calificaciones sobre las huacas de la UNI, para poder comprender cuáles son los imaginarios que se tienen sobre el patrimonio dentro de la universidad y cómo sacar provecho de él.

La base teórica de esta metodología se centra en dos autores, quienes son los siguientes:

- Armando Silva, en Metodología de trabajo, presenta la metodología utilizada para reconstruir la ciudad de Bogotá desde la mirada de los sujetos. Además, utiliza diferentes herramientas, cuestionarios y registros fotográficos, para interpretar las actividades y percepciones de las personas, asimismo, hechos que grafican la ciudad imaginada de Bogotá. 
Tabla 1. Entrevistados, expertos y no expertos que participaron en esta investigación

\begin{tabular}{|c|c|}
\hline $\begin{array}{c}\text { Gestores culturales internos y próximos al caso de } \\
\text { estudio: }\end{array}$ & \multirow{6}{*}{$\begin{array}{l}\text { Entrevista tipo } 3 \text { - Internos invo- } \\
\text { lucrados con el tema / Expertos }\end{array}$} \\
\hline Dr. José Hayakawa & \\
\hline Representante del Cismid & \\
\hline Decano de MINAS & \\
\hline Mg. Arq. Enrique Guzmán & \\
\hline Director Cultura UNI - José Miguel de Zela & \\
\hline Comunidad UNI - Nuevo Plan Director UNI 2018-2028: & \multirow{2}{*}{$\begin{array}{l}\text { Entrevista abierta sobre su ex- } \\
\text { periencia con el Plan Director } \\
\text { UNI / Expertos }\end{array}$} \\
\hline Arq. Roberto Medina & \\
\hline
\end{tabular}

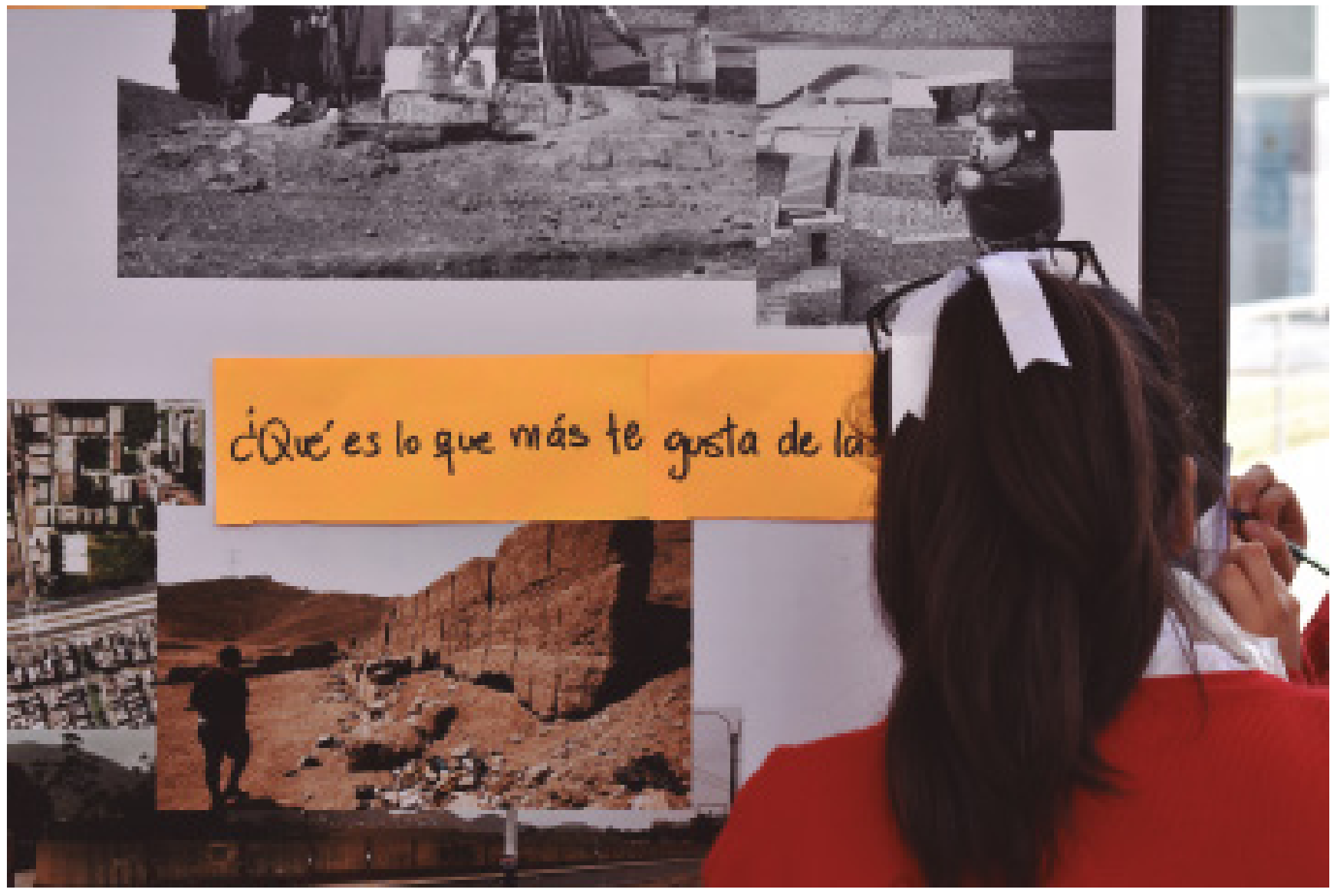

Figura 5. Fotografía tomada en la feria Qhatuni 2018. Archivo fotográfico personal, 2019. 


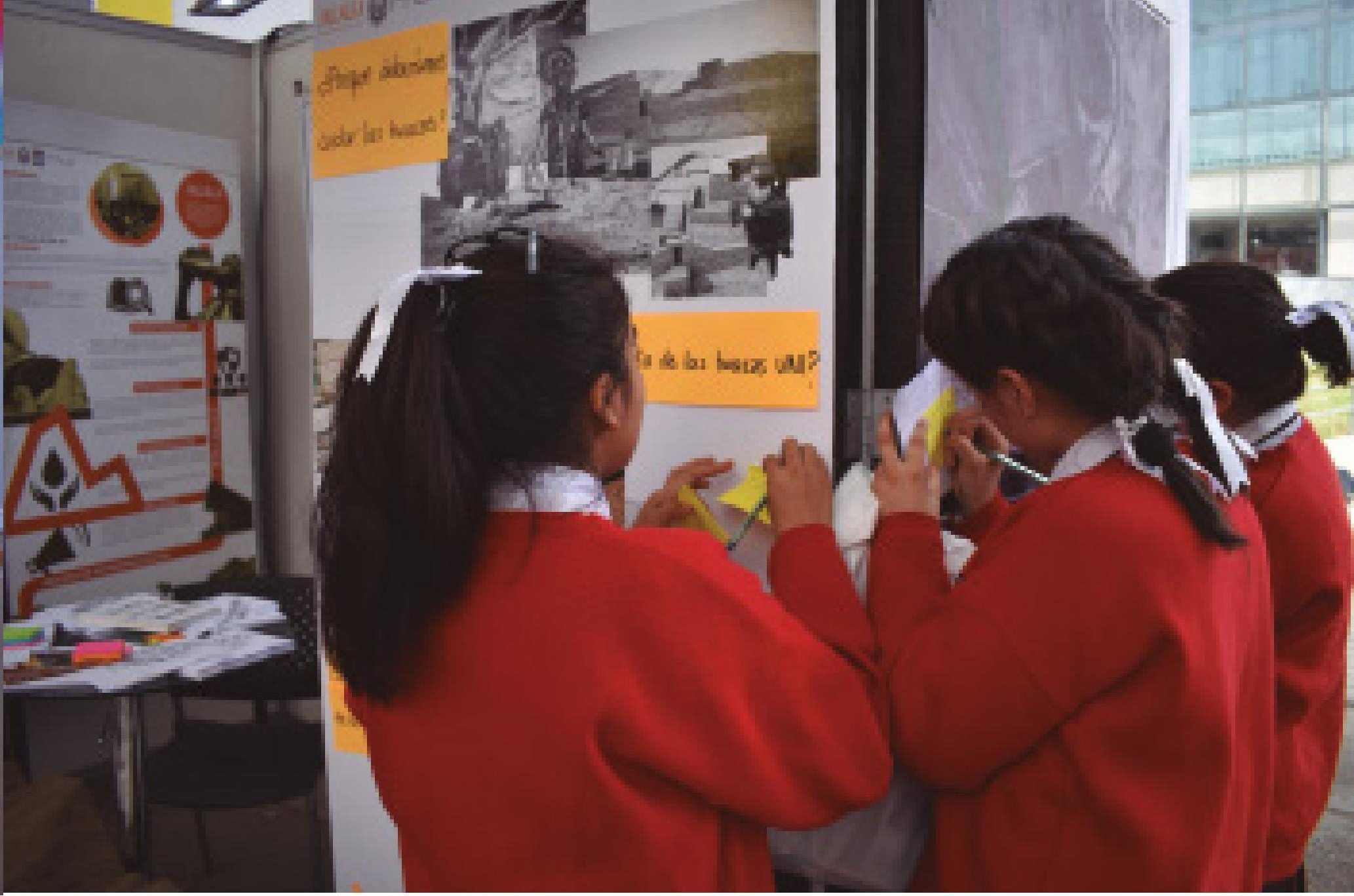

pectador, y se permite tener una doble participación en la recopilación de datos (Silva, 2006)

3. Sesiones en profundidad o grupos de enfoque. Existe un interés por parte del investigador por como los individuos forman un esquema o perspectiva de un problema a través de la interacción (Hernández Sampieri, 2010, p. 425).

4. Documentos, registros y material fotográfico. Parafraseando a Silva, cada imagen debe estar acompañada de una ficha técnica, estas fotografías también admiten una lectura desde una lógica trial que permite un desarrollo conceptual sobre lo representado para deducir marcas ciudadanas (Silva, 2006). También se aplicó para medios masivos de internet, fotografías utilizadas de páginas web, en donde se haga manifiesto de las posturas de los entrevistados.

5. Registro fotográfico personal. Es imprescindible para aportar una visión personalizada de la actividad y se puede mostrar a través de fichas y una descripción del fragmento (ver Figuras 5, 6, 7 y 8).

\section{Marco histórico referencial: contexto referencial de campus universita- rios y patrimonio prehispánico en Lima}

Es importante conocer cuáles son las reacciones de los profesionales a cargo de las principales gestiones de patrimonio prehispánico relacionados con los campus universitarios que existen en Lima. Las universidades consideradas parte del marco referencial de esta investigación fueron elegidas por la relevancia de sus acciones en torno a la valorización que se le dio a su patrimonio. Estas instituciones son las siguientes: Universidad Nacional Mayor de San Marcos, Pontificia Universidad Católica del Perú y Universidad Peruana Unión.
Figura 7. Fotografía tomada en la feria Qhatuni 2018. Archivo fotográfico personal, 2019. 
isters of erotin hom

en b LNI?
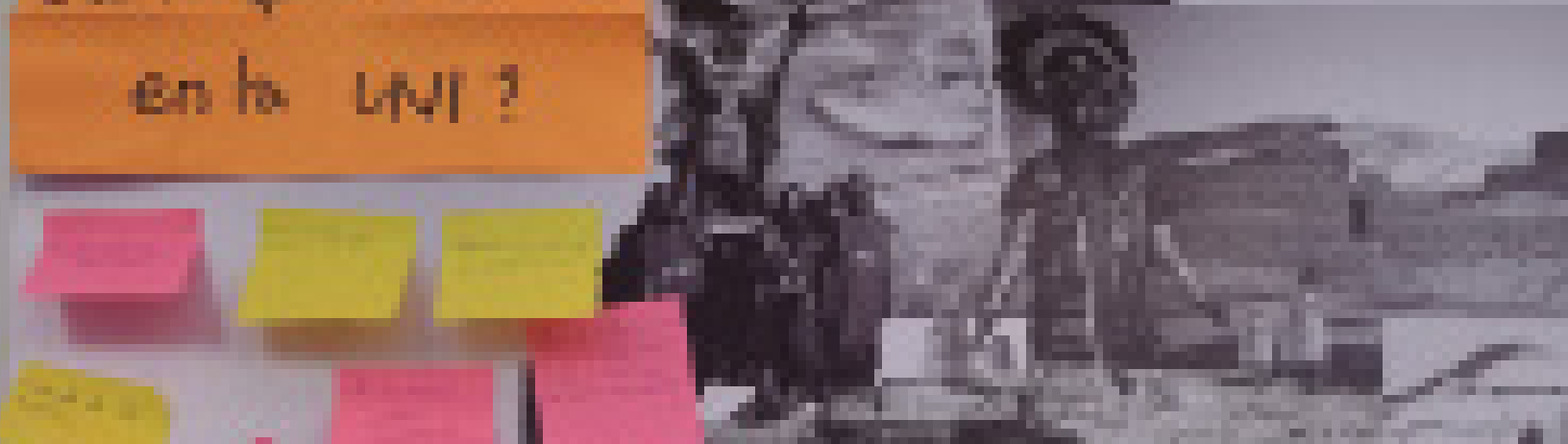

Whith

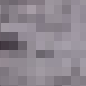

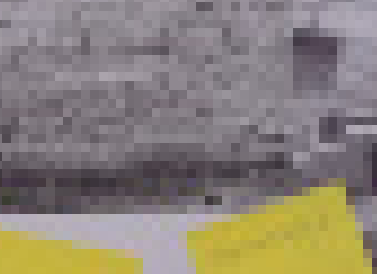
$x_{x=1}$

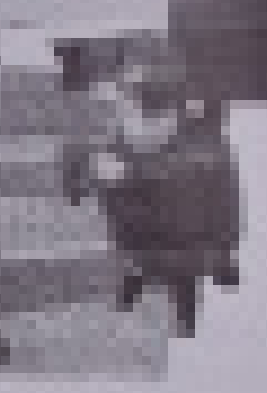

$+\frac{1}{1+n}$

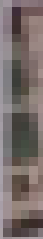

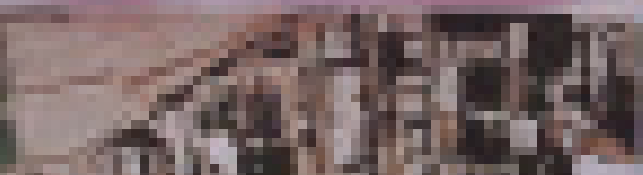

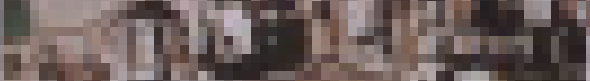

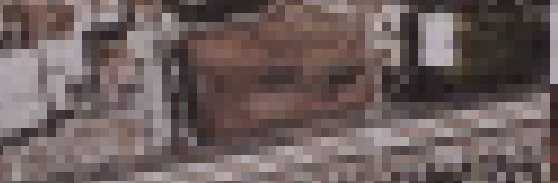

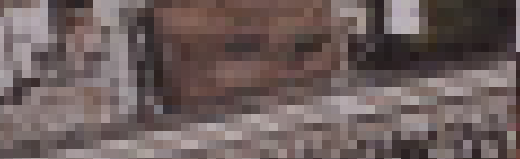

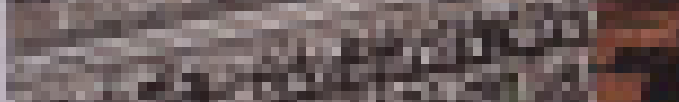

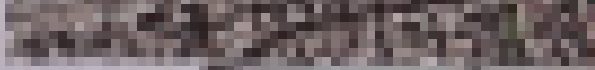
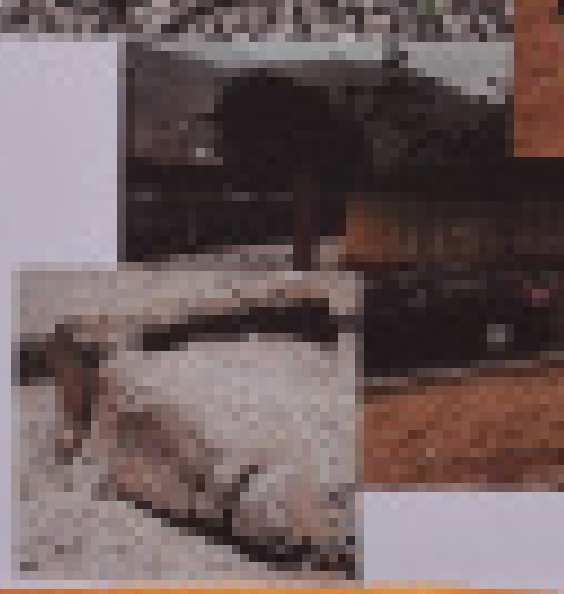

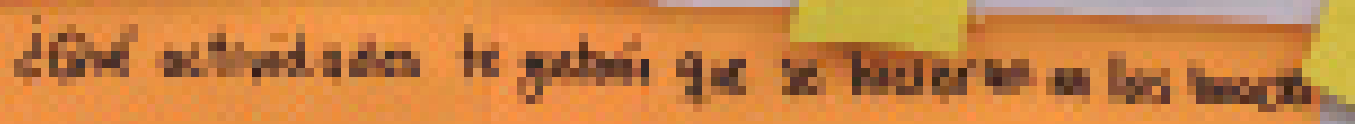

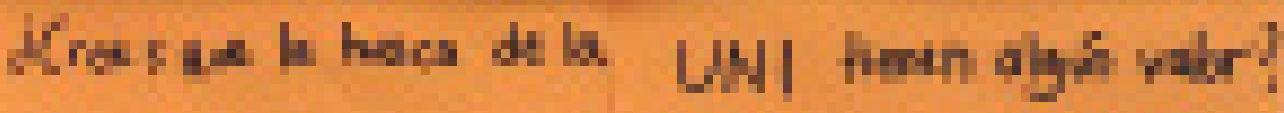

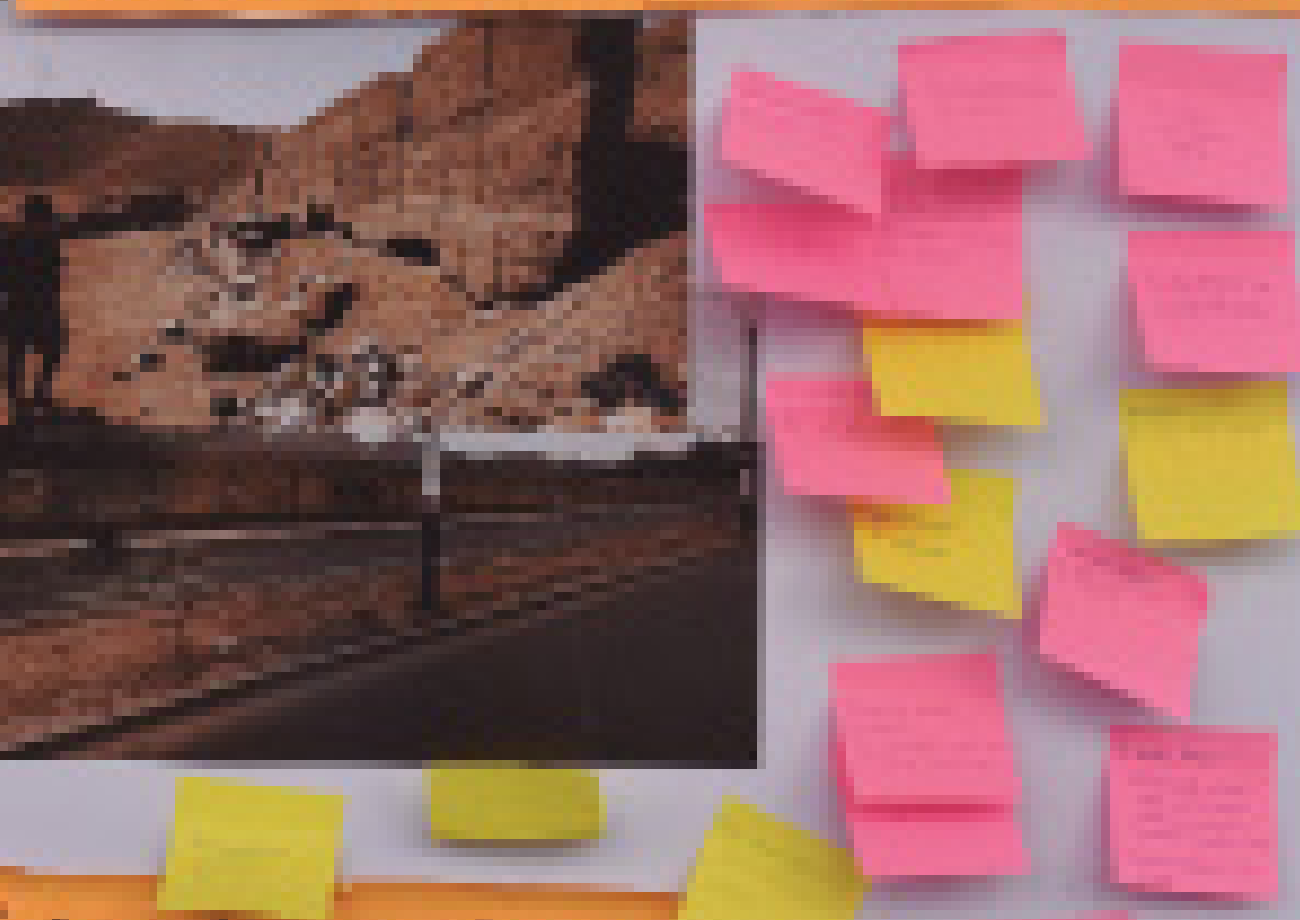




\section{La experiencia de la Pontificia Universidad Católica del Perú}

Para entender la experiencia que tiene la Pontificia Universidad Católica del Perú en el trabajo de su patrimonio prehispánico, fue fundamental entender cómo se formaron las primeras acciones referentes al cuidado y valoración del patrimonio dentro de la universidad. Al respecto, Bringas (2018) afirma lo siguiente:

Gracias a los trabajos iniciales llevados a cabo por la doctora Josefina Ramos de Cox, y a la voluntad política y el compromiso institucional de la PUCP con el patrimonio, se han realizado numerosos trabajos e investigaciones en los tres sitios arqueológicos ubicados denle el campus: Huaca 20, Huaca 64 y Camino Inca. (p. 99)

Así como en el caso de la UNI, la institucionalidad juega un rol preponderante en la toma de decisiones, para generar avances en las políticas de cuidado del patrimonio prehispánico.

En cuanto al aspecto institucional, los marcos legales establecen la responsabilidad que tiene la universidad de proteger y preservar los bienes culturales existentes en su territorio $y$, las respectivas sanciones en caso de incumplimiento. Además, la gestión integral del patrimonio supone no solo acciones de conservación, sino también su utilización (tangible e intangible) según las necesidades actuales. (Bringas, 2018, p 106)

Finalmente, Bringas menciona las funciones que debe cumplir la universidad que tiene el reto de contar con un patrimonio, y qué beneficios traería la toma de conciencia de esta realidad.

La universidad debe cumplir funciones usualmente atribuidas a museos y otras instituciones responsables del patrimonio: identificación, documentación, conservación, estudio, presentación e interpretación. Todas estas responsabilidades se condicen con lo expresado en la Ley Universitaria peruana; por ello, la gestión del patrimonio arqueológico debería ser una de las prioridades institucionales. En ese sentido, un desafío importante consiste en construir una política, y un plan de gestión del patrimonio cultural presente en el campus de la universidad a mediano y largo plazo. (Bringas, 2018, p. 106)

\section{La experiencia de la Universidad Peruana Unión}

En el caso de la Universidad Peruana Unión (UpeU), la toma de conciencia de este patrimonio prehispánico estuvo más relacionada con la participación ciudadana, ya que, por la ubicación de esta huaca, los pobladores lograron generar vínculos afectivos con el patrimonio evocando a su pasado prehispánico, y se centraron en las principales reglas de comunidad del manuscrito de Huarochirí y otras expresiones culturales andinas.

Debido a su ubicación estratégica, la UPeU no solo ha servido como protección para la zona arqueológica Unión-Ñaña ante los conflictos territoriales que tienen lugar en estos intersticios urbanos (producto de la tensión entre el avance informal de la periferia urbana sobre los remanentes de áreas rurales y patrimoniales), sino que también ha permitido el uso de los cerros aledaños como áreas recreativas por parte de la comunidad estudiantil. Así mismo, la universidad promueve la investigación de este paisaje prehispánico desde hace dos décadas. (Del Castillo y Sopla, 2018, p. 172)

Estos resultados revelan la importancia de ahondar en lecturas multidisciplinarias de las narraciones sagradas de la cosmovisión andina (como aquellas contenidas en el Manuscrito de Huarochirí), y su relación con el paisaje de esta localidad y el valle que la alberga. Así, se reivindica una visión del patrimonio que va más allá del objeto arquitectónico y/o arqueológico, y trasciende hacia la escala del paisaje, lo cual permite tener un mejor entendimiento del rol de estos sitios en el manejo del territorio y la predicción de fenómenos climáticos en tiempos prehispánicos. (Del Castillo y Sopla, 2018, p. 172) 
devenir Vol.6, N¹2, JULIO-DICIEMBRE 2019, PP. 155-178 - EstUDIOS | ISSN 2312-7562 | E-ISSN 2616-4949

UNIVERSIDAD NACIONAL DE INGENIERÍA, LIMA

doi: https://doi.org/10.21754/devenir.v6i12.748

Tabla 2. Matriz de resultados de entrevistas sobre patrimonio prehispánico en las universidades del marco referencial.

\section{Lic. Andrea Bringas - PUCP}

\section{Dra. Luisa DÍaz - UNMSM}

\section{Mg. Arq. Juan Manuel del Castillo - UPEU}

\begin{tabular}{ll}
\hline & \\
& "La posibilidad de ver al patrimonio \\
prehispánico dentro del campus como "Creo que la universidad es el espa- \\
una oportunidad que va a enriquecer cio más adecuado para desarrollar lo \\
la formación integral de los estudiantes que es la conservación, preservación, \\
es una manera de fortalecer una valo- puesta en valor y paralelamente usar- \\
ración importante, que tal vez no se ha lo en la docencia (...)" \\
desarrollado en el colegio..."
\end{tabular}

"Puedo decir que, la universidad es el lugar ideal para crear un modelo para convivir con el patrimonio (...) se debería promover desde la universidad no solo la investigación científica, sino el uso social del patrimonio por la misma comunidad universitaria. Enseñar que las huacas son un lugar que pueden convivir perfectamente con el espacio público, la naturaleza, el conocimiento y la investigación (...) eso es un tremendo regalo que tienen las múltiples disciplinas de la universidad." prioridad en los recursos para intervenir. Ya hay un nivel importante de sensibiliza-

Fortalezas y ción de parte de los funcionarios PUCP." debilidades "Una debilidad es que aún está en proceso hacer un plan de gestión de patrimonio arqueológico en la universidad."
"La fortaleza es que tenemos una escuela de arqueología, la más antigua del país. Tenemos profesionales especialistas que podrían hacer una gran gestión. "Nuestras debilidades son intrínsecas a la administración de la universidad, para lograr una adquisición, el proceso es larguísimo, y además hay muchos cambios de autoridades, eso ha ido cambiando."
"Un de las principales fortalezas de Ñaña es que es un paisaje intersticial, entre lo rural y urbano. Y en este caso lo importante es que la zona Unión Ñaña, la universidad ha crecido y eso ha protegido la zona arqueológica. Por otro lado está el tema identitario. Hay una suerte de identidad entre el ande y la costa. Es uno de los más importantes observatorios ancestrales de la costa peruana"
Educacion patrimonial
"Hay factores claves que se vinculan con el patrimonio en la universidad, en un primer momento solo arqueología, luego se vincularon algunos estudiantes de otras carreras que no eran afines a la arqueología pero que mostraban un interés por el patrimonio y la inclusión de sus trabajos y reflexiones desde la universidad "
"La ciudad de Lima es tan caótica, eso te impide tener sensibilidad de apreciar la cultura, pero al poder revitalizar se puede ir aprendiendo del pasado. (...) La cultura le da una dimensión humana a las cosas, y eso llena un aspecto de la vida que nos hace ser mejores ciudadanos."
"Sabiendo que la huaca está dentro de la UNI, yo creo que debería ser una obligación de la universidad y el ministerio poder ponerlas en valor. Además teniendo una facultad de arquitectura eso debería ser un aliciente mayor."
Valores patrimoniales

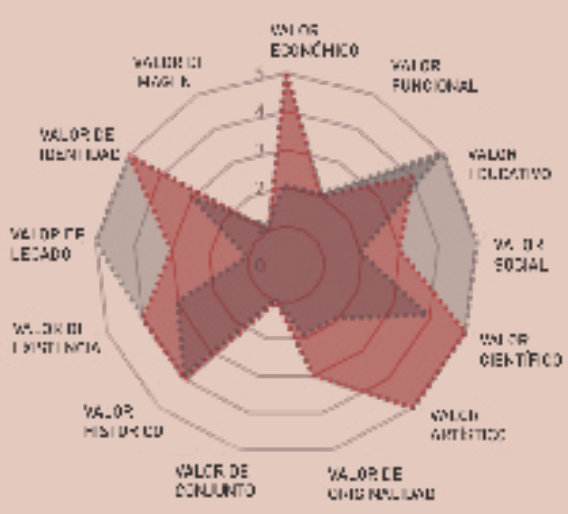

\section{J411-}

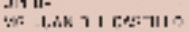

\section{IIIMTW}

DPR LUSA CLR:

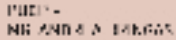

Elaboración propia sobre la base de entrevistas (citas textuales). Adaptado de la tabla de valores patrimoniales de Montañez (2016). 


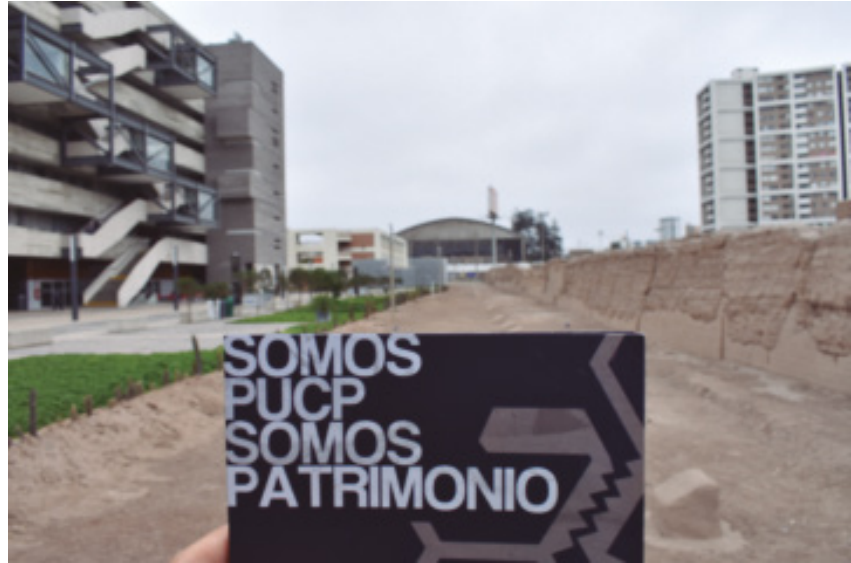

Figura 9. Fotografía Patrimonio prehispánico de la PUCP. Archivo fotográfico personal, 2018.

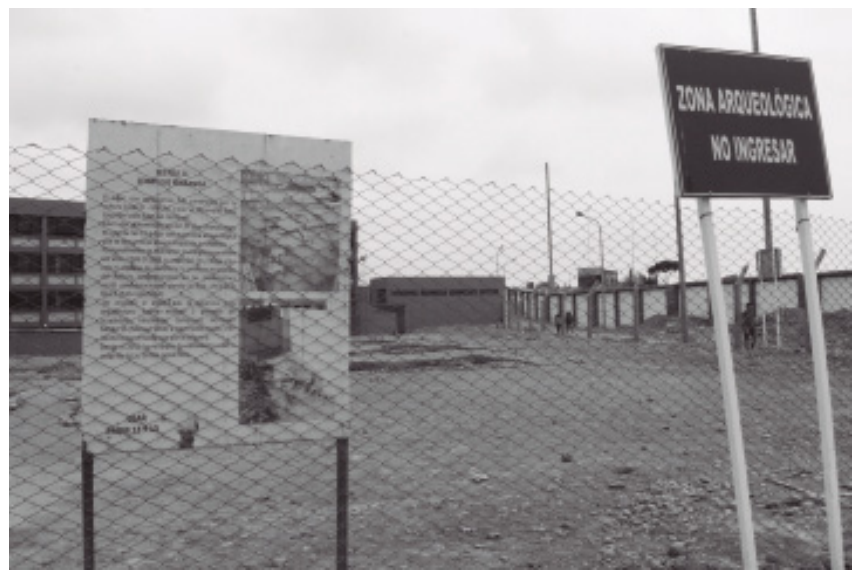

Figura 11. Fotografía Patrimonio prehispánico de la UNMSM. Archivo fotográfico personal, 2018.

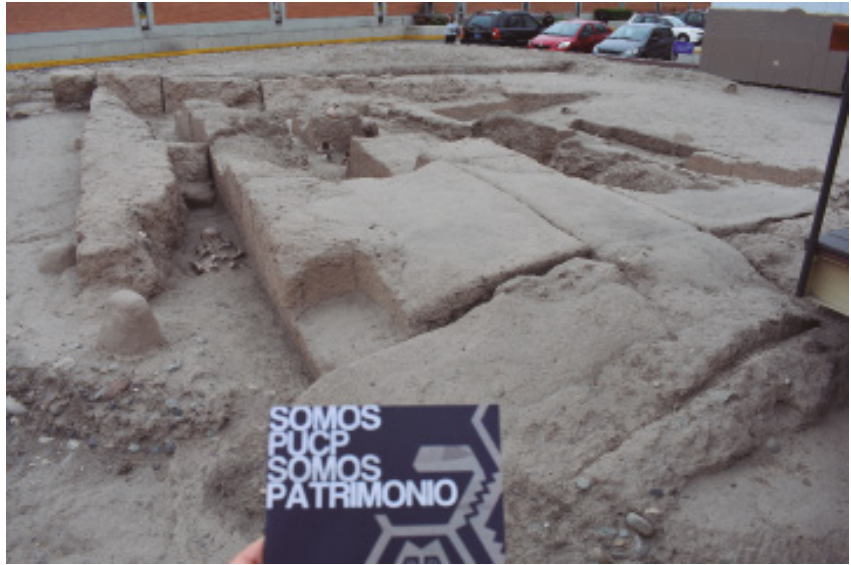

Figura 10. Fotografía Patrimonio prehispánico de la PUCP. Archivo fotográfico personal, 2018.

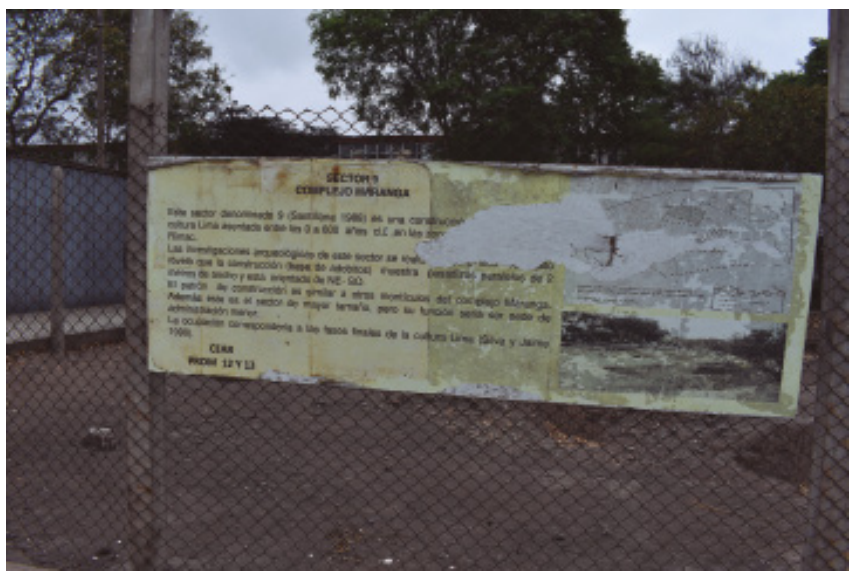

Figura 12. Fotografía Patrimonio prehispánico de la UNMSM. Archivo fotográfico personal, 2018.

\section{La experiencia de la Universidad Nacional Mayor de San Marcos}

La Universidad Mayor de San Marcos (UNMSM) tiene un caso similar al de la UNI. La principal similitud que tienen es que las dos son universidades financiadas por el Estado peruano. Esto les da una característica institucional parecida; sin embargo, es importante mencionar que la UNI es una universidad tecnológica, con un componente académico humanístico reducido. Mientras que en la UNMSM existe un porcentaje de carreras humanísticas que permitirían trabajar de la mano con el patrimonio prehispánico, lo cual está en proceso de desarrollo (ver Tabla 2 y Figura 9, 10, 11 y 12).

\section{Marco de referencia: El Plan Director de la UNI y el patrimonio prehispánico}

El Plan Director de la UNI 2018-2028 es un texto de planificación y visión del campus universitario de la UNI, el cual trata sobre los principales cambios de infraestructura y un modelo de campus autosostenible, con una visión al 2028.

Asimismo, el Plan Director realiza consideraciones con respecto a las huacas de la UNI, las cuales se mencionarán a continuación. 
devenir Vol.6, N¹2, JULIO- DICIEMBRE 2019, PP. 155-178 - EstUDIOS I ISSN 2312-7562 | E-ISSN 2616-4949

UNIVERSIDAD NACIONAL DE INGENIERÍ, LIMA

doi: https://doi.org/10.21754/devenir.v6i12.748

En el capítulo 3, denominado Propuestas de cambio-campus UNI, se manifiesta brevemente cuáles son las acciones referidas al patrimonio prehispánico de la Universidad.

Tratamiento de acondicionamiento, rehabilitación y refuerzo estructural de edificaciones emblemáticas de la UNI. Incluyen coordinaciones con el Ministerio de Cultura para la puesta en valor de las Huacas Cismid y Minas. (Plan Director UNI, 2018, p. 31, )

Integrar la vida académica con lo cultural, recreativo y otros servicios: Las tasas de éxito de los estudiantes están fuertemente influenciadas por los programas de vida estudiantil y residencial en el campus. Este Plan Director manifiesta el compromiso de la universidad a proporcionar servicios de calidad a la comunidad universitaria, y donde las concentraciones de la actividad académica también deben ser revisadas. (Plan Director UNI, 2018, p. 33)

Pese a lo genérico que es el Plan Director (2018) con respecto a los impactos que genera el empoderamiento de la comunidad universitaria en temas de patrimonio. En este caso particular, con las infinitas oportunidades que nos dan las huacas de la UNI, para fomentar educación y cultura, es importante mencionar que ya existe una voluntad para proponer acciones que incluyan al patrimonio prehispánico a la vida universitaria. Sin embargo, estas reflexiones extendidas en el Plan Director son en cuanto a la infraestructura, mas no considera la reflexión humanística (ver Tabla 3).

\section{Marco teórico: Una nueva teoría para los nuevos retos de la universidad}

Para entender la universidad y cómo esta se relaciona con las dinámicas de la ciudad y sus habitantes, se abordarán los temas de universidad como espacio intramuros y una nueva teoría de universidad.

\section{La universidad como un espacio intramuros}

Revelando los principales pensamientos de las ciudades universitarias fue que pudimos encontrar que algunos autores ya concebían la universidad como un objeto obsoleto si se piensa en ella en función de las personas. Al respecto, Castillo de Herrera (2011) menciona: «La universidad se encuentra abocada a su desaparición si no conserva, recree y desarrolle para los tiempos de hoy los roles para que es insustituible e irremplazable y que tradicionalmente ha jugado desde su nacimiento» (p. 93).

Siendo más incisivos en el tema de las relaciones humanas existentes en la universidad, Campos Calvo-Sotelo (2011), un autor que fue de gran valor para esta investigación, afirma lo siguiente: «La universidad no puede ya únicamente circunscribirse al campus, edificio o aula, sino que ha de ser consciente de su responsabilidad para con el conjunto del contexto social» (pp. 168-169).

Otros autores ya habían revelado a la universidad como un sistema vivo, como hace referencia Indovina (2006):

La universidad que necesitamos es una universidad como laboratorio permanente de innovación y de formación, centrada en el interés de la totalidad de la sociedad, atenta a valores históricos y ambientales, caracterizada por una fuerte tensión democrática y de justicia social, capaz de medir los beneficios de los resultados de la investigación en términos de ventajas colectivas (para todos). (p. 39)

\section{Entre el patrimonio y su influencia en la universidad}

Cuando se logra entender que la universidad es un lugar donde coexiste la historia de una parte de la ciudad, entonces la propia universidad reconoce que tiene un papel importante en el desarrollo de la sociedad. 
Tabla 3. Patrimonio prehispánico del Campus UNI

\begin{tabular}{lll}
\hline $\begin{array}{c}\text { Denomina- } \\
\text { ción }\end{array}$ & $\begin{array}{c}\text { Nombre de la } \\
\text { zona }\end{array}$ & \multicolumn{1}{c}{ Descripción y proyectos estratégicos } \\
\hline ZTE 1 & HUACA UNI-Cismid & $\begin{array}{l}\text { Coordinaciones con el Ministerio de Cultura para la puesta } \\
\text { en valor de la Huaca UNI-Cismid, incluyendo cambios de } \\
\text { nombre. } \\
\text { PEE1.- Puesta en valor de la Huaca UNI CISMID y entorno. } \\
\text { PEE2.- Edificación nueva del museo de sitio. }\end{array}$ \\
ZTE 2 & HUACA UNI-minas & $\begin{array}{l}\text { Coordinaciones con el Ministerio de Cultura para la puesta } \\
\text { en valor de la Huaca UNI-minas. Demolición de edificación } \\
\text { anexa sin uso. } \\
\text { PEE1.- Puesta en valor de la Huaca UNI-minas y entorno. } \\
\text { PEE2.- Edificación nueva del museo de sitio. }\end{array}$ \\
\hline Tomado del Plan Director de la UNI, 2018. &
\end{tabular}

Asimismo, se citó algunos extractos de la publicación de la Universidad de Alcalá (patrimonio mundial) y se reflexiona sobre el tema del patrimonio en la universidad:

Una vez se alcance el derecho de todos a la ciudad patrimonial, Alcalá de Henares Patrimonio de la Humanidad, además de comportarse como laboratorio experimental para la investigación innovadora y la solución de problemáticas urbanísticas, deberá ser ejemplo exportable de gestión comunitaria, a partir del compromiso colaborador de todas las estancias públicas y privadas en un proyecto colectivo de participación efectiva de grupos vecinales. (Ibáñez, 1999, p. 60)

En el mismo texto también menciona a la Universidad de Alcalá y cómo se puede generar un impacto con su patrimonialización:

La universidad como ciudad del saber, configura un conjunto urbano singular cuyo espacio de conocimiento sobrepasa con largueza los muros de la propia Alcalá de Henares. El saber así entendido es no solo un recurso patrimonial, sino una fuente de posibilidades de amplia repercusión en la sociedad de servicios que vivimos. [...] En este sentido amplio de lo urbano y de los patrimonial, la universidad ya ha roto los limites externos que la definían y limitaban, convirtiéndola en una institución de gestión capaz de acometer todo tipo de proyectos y en consecuencia de colaborar y difundirse en el territorio como no podía ser en el pasado. (Ibáñez, 1999, p. 61)

Finalmente, en el texto se hace una reflexión muy relevante sobre la tarea del patrimonio en la universidad, y cómo este es aprovechado de múltiples maneras de las cuales se puede inferir su real importancia para la ciudad que queremos alcanzar.

El patrimonio es así una tarea, una necesidad socio-económica y una contribución que recupera e incorpora a la lectura presente del pasado el significado de la biografía remota o inmediata, es un aprendizaje. Tiene que ver con formas de cómo vivir, de cómo construir el imaginario colectivo, y con ello de como instrumentalizar su papel en las escalas territoriales, regionales, nacionales. (Ibáñez, 1999, p. 62)

\section{Los nuevos retos del patrimonio en la actual sociedad}

Los objetos considerados dentro de la esfera patrimonial son valiosos, porque las personas les atribuyen ciertas cualidades que desean preservar para la posteridad, por tratarse de objetos con peculiaridades singulares. A su vez, se vinculan a una comu- 
devenir Vol.6, N¹2, JULIO-DICIEMBRE 2019, PP. 155-178 - EstUDIOS | ISSN 2312-7562 | E-ISSN 2616-4949

UNIVERSIDAD NACIONAL DE INGENIERÍA, LIMA

doi: https://doi.org/10.21754/devenir.v6i12.748

nidad particular y a sus descendientes. En un momento concreto se piensa que su conservación hará más felices a los presentes y futuros herederos (Nieto, 2018, p. 125).

Howard, (citado en Villamn, 2017) se señala que Not everything is heritage, but anything could become heritage. (Villamn, 2017, p. 128)

Howard (citado en Villamn, 2017) afirma lo siguiente: «Heritage is for people, not just for a smaII minority of specialists and experts, but for everyone». (Villamn, 2017, p. 132)

En cuanto a la búsqueda de enfoques del patrimonio, además de su común relación con el pasado, se encuentra la propuesta de Howard (2003) de considerar el patrimonio en sí mismo como una disciplina aplicada: «Heritage is not about the past. Of course, many of the objets and the ideas with wich it deals come from the past, but heritage issues are always about what we do whit them now». (Villamn, 2017, p. 126-127)

En este punto es imprescindible citar una reflexión de Feliu (2014), quien se refiere a los principios de los nuevos retos del patrimonio:

Conservar el patrimonio nos hace felices:

Es decir, hacer que otros aprecien y disfruten de lo mismo que queremos nos gusta, nos hace felices, y esa es la razón por la que queremos que el patrimonio que valoramos sea trasmitido a generaciones futuras. Conservar el patrimonio para ser felices; creo que no hay mejor justificación. (p. 14)

La educación es uno de los pilares por los cuales la universidad fue creada, para entender la dimensión que tiene la educación y su relación con el patrimonio enumeraremos algunas citas.

La tesis doctoral de Nieto (2018) se define a la educación de la siguiente manera:

Educación puede definirse como el proceso de socialización de los individuos. Al educarse, una persona asimila y aprende conocimientos. La educación implica una concienciación cultural y conductual, donde las nuevas generaciones adquieren los modos de ser de las generaciones anteriores. (p. 133)

En cuanto a las relaciones entre el patrimonio y la educación, como se citó en Nieto (2018) menciona el Plan Nacional de Educación y Patrimonio de 2016, en el cual se sostiene lo siguiente:

Educación y Patrimonio o educación patrimonial. Este enfoque de carácter globalizador, integrador y simbiótico coloca el acento en la dimensión relacional existente, no solo entre ambos términos, sino entre los elementos que integran o constituyen cada uno de ellos. De este modo, si los bienes culturales que forman parte del patrimonio son considerados como tales en virtud del acto de patrimonialización realizado por el colectivo o sociedad que es su titular, es decir en virtud de la relación existente entre estos bienes y las personas que los dotan de valores culturales, la educación patrimonial es doblemente relacional, pues la educación se ocupa de las relaciones entre las personas u aprendizajes. Así el patrimonio es el contenido de ese aprendizaje y de las formas de relación se refieren a la identidad, la propiedad, el cuidado, disfrute, transmisión, etc. (p. 134)

Acerca del empoderamiento patrimonial y cómo se logra, el mencionado autor manifiesta lo siguiente:

Empoderamiento patrimonial, que convierta a los alumnos - futuros ciudadanos - en miembros responsables del uso, cuidado y preservación a próximas generaciones de los bienes culturales. Así se facilita:

- El conocimiento crítico y reflexivo del patrimonio, 
- Promoción de los valores relacionados con la defensa de la diversidad cultural,

- Fomento de la empatía cultural,

- Accesibilidad y democratización cultural: se tendera a la socialización del Patrimonio. (Nieto, 2018, p. 136)

\section{Una nueva teoría acerca de la universidad}

En relación con las cuatro escalas del aprendizaje didáctico, Campos Calvo-Sotelo sostiene lo siguiente:

La universidad es un organismo que se implanta mediante una estructura de espacios habitualmente compleja y diversificada.

- Primera escala: La escala urbanística, como ensamblaje de la Universidad- ciudad.

- Segunda escala: La escala de recinto universitario, como conjunto diferenciado vivencial

- Tercera escala: La escala del edificio, como pieza de arquitectura integrada en el campus

- Cuarta escala: La escala del aula, como unidad espacial básica de enseñanza - aprendizaje.

(Campos Calvo-Sotelo, 2011, p. 169)

Asimismo, se reconoce la reestructuración de universidad como un estudio de cuatro escalas que tratan de ensamblar a la universidad (entidad física) a su planeamiento urbano y, también, su repercusión social. Por ello, esta investigación propone que se considere una nueva escala entre la tercera y la cuarta escala, que incluiría al patrimonio, como una relación tan importante y básica como la que es la de universidad-ciudad, es así que esta escala intermedia sería la siguiente: Escala intermedia: La escala de la universidad y el patrimonio.

En decir, la universidad tiene la labor de promover la educación patrimonial, además de tener el reto de involucrar a la población universitaria a la apropiación de su patrimonio, y así desarrollar proyectos de investigación que ayuden a las exigencias que tiene la ciudad.

En consecuencia, el reto es la integración de los planes universitarios a la conservación y valorización del patrimonio arqueológico de los campus universitarios, y así considerar la «huaca» como una oportunidad de cambio y mejoras (ver Tabla 4).

\section{Presentación de resultados}

Luego de la utilización de las diferentes técnicas utilizadas en la metodología de trabajo, a continuación se exponen, a través de tablas y gráficos, los resultados del trabajo de campo (ver Tabla 5, 6 y Figuras 13, 14).

\section{Interpretación de resultados}

Luego de la revisión y análisis inicial de los resultados de esta investigación, se observa, en primer lugar, que existe un gran interés de la comunidad universitaria por participar activamente de la recuperación de su patrimonio prehispánico. Para entender los resultados, se realiza esta clasificación en dos categorías:

- El objeto de estudio y su relación con los sujetos patrimoniales.

- La visión patrimonializadora del colectivo Jallalla

\section{El objeto de estudio y su relación con los sujetos patrimoniales}

A partir del estudio realizado, se afirma que existe un número importante de personas que conocen la existencia del patrimonio prehispánico de la UNI. Además, existe un 
devenir Vol. 6, N¹2, JULIO- DICIEMBRE 2019, PP. 155-178 - EsTUDIOS I ISSN 2312-7562 | E-ISSN 2616-4949

UnIVERSIDAD NACIONAL de INGENIERÍA, LIMA

doi: https://doi.org/10.21754/devenir.v6i12.748

Tabla 4. Análisis explicativo de las escalas del nuevo concepto de universidad para Campos Calvo-Sotelo

\section{Descripción de las esca- las del aprendizaje}

Definiciónde la escala determinada
Relación con la realidad problemática UNI según la autora
Para Campos Calvo: Primero, sugiere la metáfora sobre la transparencia de la institución como entidad abierta al conjunto de la sociedad.

Para Campos Calvo: Segundo, se fomenta la curiosidad del público Tercera La escala del edificio, como en general, enfocados al aprendizaje creativo. escala pieza de arquitectura integrada en el campus

Tercero, se estimula la curiosidad de los estudiantes hacia el trabajo y los progresos de sus compañeros, en definitiva hacia la propia actividad universitaria. Cuarto, se habilita una mayor permeabilidad de las relaciones sociales.
La patrimonializacion del campus UN Desde el 2017 existen esfuerzos de profesores, la comunidad universitaria y funcionarios UNI por ver a la universidad como una unidad de gran valor patrimonial. El colectivo Jallalla ha promovido investigacion y eventos culturales para la comunidad universitaria y externos en general.
Escala intermedia propuesta

La escala de la universidad y el patrimonio
La universidad debe ser partícipe de la implementación de la educación patrimonial, además de promover la cultura y la identidad del pasado prehispánico como en muchas universidades del mundo. La huaca como pieza integrada al campus y como oportunidad de cambio.
El reto de la UNI y su patrimonio: La recuperación del patrimonio por parte de jóvenes universitarios interesados formó el colectivo Jallalla, el cual está comprometido con el cuidado y difusión del patrimonio UNI. Actualmente las autoridades de la universidad tambien han participado de estas actividades culturales.
Para Campos Calvo: El aula debe fomentar el aprendizaje activo, quizá de un modo especialmente comprometido. Así, una cierta estructuPara Campos Calvo: ra interna del aula permite estudiar la composiLa escala del aula, como uni- ción de sus elementos con criterios tipológicos, dad espacial básica de ense- basados en la complejidad, variabilidad y ñanza - aprendizaje
Las aulas de la UNI Debemos contribuir a repensar el uso de la infraestructura de la universidad, con la intención de que no solo nos sirva como un medio de aprendizaje sino que esté involucrado con el desarrollo integral del alumno. Proyectar espacios donde el debate $y$ pensamiento critico esten presentes para colaborar con el desarrollo del pais, empezando con la reflexion de nuestro campus. 
Tabla 5. Matriz de resultados expertos consultados en el tema de estudio.

\begin{tabular}{|c|c|c|c|}
\hline & $\begin{array}{c}\text { Dr. Arq. Jose Hayakawa Casas - } \\
\text { DIRECTOR INIFAUA }\end{array}$ & $\begin{array}{l}\text { Msc. Arq. Enrique Guzman - } \\
\text { DOCENTE FAUA }\end{array}$ & $\begin{array}{l}\text { Lic. José Miguel de Zela - } \\
\text { CULTURA UNI }\end{array}$ \\
\hline Reflexiones & $\begin{array}{l}\text { "Creemos que el encargo de pensar } \\
\text { el patrimonio de la universidad tiene } \\
\text { presencia en el grupo de investigación } \\
\text { Yuyay. Que es el grupo de investigación } \\
\text { de patrimonio de la UNI, es una buena } \\
\text { noticia, pero claro (...) tendría que ser } \\
\text { acompañado de un presupuesto y una } \\
\text { institucionalidad que le pueda dar sos- } \\
\text { tenibilidad a la actuación." }\end{array}$ & $\begin{array}{l}\text { "Los espacios que se han creado y son } \\
\text { parte de la vida universitaria, no de- } \\
\text { berían sufrir atropellos. (...) Entonces, } \\
\text { ante eso quizás la universidad debería } \\
\text { tener, como se está haciendo (...) un } \\
\text { Plan Maestro, para manejar esos espa- } \\
\text { cios y edificios." }\end{array}$ & $\begin{array}{l}\text { "El primer desafío que tiene la UNI es la } \\
\text { puesta en valor. Primero no amurallar sino } \\
\text { sociabilizar el patrimonio. EI bien cultural } \\
\text { debe ser social, debe haber una conciencia } \\
\text { del mismo. Toda la comunidad UNI debe } \\
\text { entender el valor a través de los espacios } \\
\text { del campus. Al crear actividades se crean } \\
\text { los vínculos entre la actividad y el quehacer } \\
\text { universitario. (...)" }\end{array}$ \\
\hline
\end{tabular}

" (...) La UNI tiene una serie de fortalezas que pasan sobre todo por las ingenierías, ciencias y donde el mundo de

Fortalezas y las artes las humanidades es más bien debilidades minoritario (...) creemos que el apoyo desde la institucionalidad puede ser mucho más importante del que es en este momento"
"Cualquier campus universitario ,la mayoría si tú viajas a Europa o Estados Unidos (...) la mayoría de los campus son abiertos, son ciudades universitarias, o sea la gente puede entrar o salir, es como si la UNI no tuviese cerco y la gente pudiese circular"
"Genero una visión integradora y articuladora del campus a través de un patrimonio vivo donde luego se empieza a colocar muros en vez de crear un uso social, en vez de acercar al patrimonio a la gente" "Creo que si la visión cambia, esto será una gran oportunidad para poder hacer una cultura dentro de la UNI y eso le daría un giro de 360 grados a toda la universidad."

\begin{tabular}{lll}
\hline & "(...) Hay que involucrar a la comunidad & "Muchos extranjeros se enteran que \\
en una idea y un sentimiento, un senti- & Lima tuvo un patrimonio importante \\
do de pertenencia que les haga sentir- & por Maranga, Pachacamac, ellos se \\
se orgullosos de estudiar aqui. (...) Pero & preguntan: ¿Ustedes porque no traba- \\
Educacion pa- & la UNI no solamente son los cursos de & jan su patrimonio y los asentamientos \\
trimonial & ingeniería, mecánica y física. También & que están en su entorno? (...) Realizan \\
& tiene que ver con el patrimonio edifica- & muchas reflexiones concernientes que \\
do, es importante que se pueda trabajar & en Lima se piensa mas en arquitectura \\
en esa línea. (...) La idea es que todo el & moderna, estilos, el tema postmoder- \\
campus se vuelva una especie de súper & no y lo sostenible y se ignora lo pre- \\
& laboratorio de estudio. " & hispanico (...)"
\end{tabular}

"Se habla mucho que el alumno UNI, es tímido y retraído (...) es mentira, lo que falta es darle el valor de la identidad. Si se lo damos a nivel cultural, podemos lograr que la autoestima se dispare y ahí todo cambia. (...) Tendríamos un profesional con una formación mucho más integral, una identidad clara y además capaz de intervenir (...) La oportunidad de resolver problemas reales dentro del campus es vital."
Valores patrimoniales

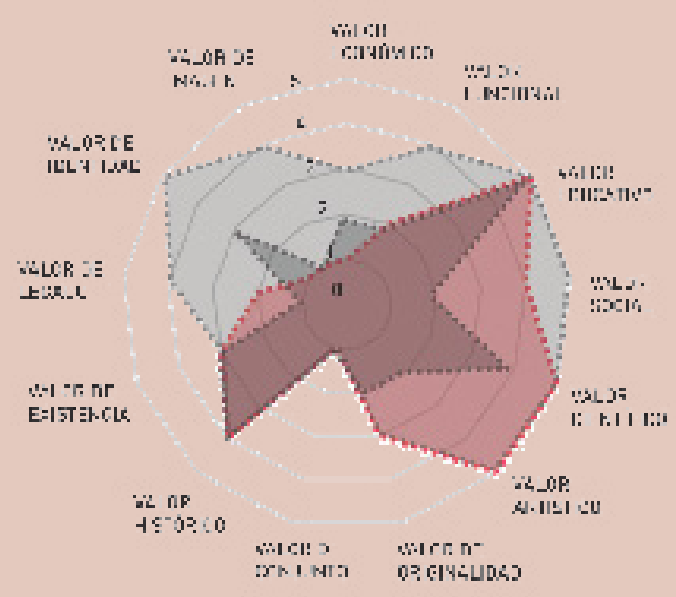

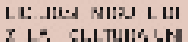

W:WT. EHAQ.E

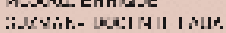

ר

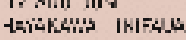


devenir Vol. 6, N¹2, JULIO- DICIEMBRE 2019, PP. 155-178 - EsTUDIOS I ISSN 2312-7562 | E-ISSN 2616-4949

UNIVERSIDAD NACIONAL DE INGENIERÍA, LIMA

doi: https://doi.org/10.21754/devenir.v6i12.748

Tabla 6. Matriz de resultados no expertos consultados en el tema de estudio

\begin{tabular}{|c|c|c|c|}
\hline & $\begin{array}{l}\text { Dr. Francisco Ríos - Miembro } \\
\text { Cismid }\end{array}$ & $\begin{array}{l}\text { Ing. José Corimanya - Decano } \\
\text { FIMGM }\end{array}$ & $\begin{array}{c}\text { Msc. Arq. Roberto Medina - Miembro } \\
\text { OCPLA }\end{array}$ \\
\hline Reflexiones & $\begin{array}{l}\text { «No puede haber universidad si n o } \\
\text { hay investigación, y las investigaciones } \\
\text { deben publicarse, porque si hacemos } \\
\text { investigación y no la difundimos, no } \\
\text { tiene sentido. Hay que profundizarlas. } \\
\text { Ojalá que en el futuro se puedan hacer } \\
\text { investigaciones en la huaca». }\end{array}$ & $\begin{array}{l}\text { «No existen opiniones negativas de los } \\
\text { alumnos acerca de las huacas, por in- } \\
\text { termedio del Ministerio de Cultura se } \\
\text { ha ido cuidando el mejoramiento de la } \\
\text { Huaca UNI MINAS. Además de estar en } \\
\text { nuestra Facultad, hay un interés positi- } \\
\text { vo hacia ella». }\end{array}$ & $\begin{array}{l}\text { «El patrimonio prehispánico es importante para } \\
\text { el equipo del Plan Director, para fortalecer la } \\
\text { identidad del campus y la de los que trabajan en } \\
\text { él. Por tal motivo, se tiene un pequeño capítulo } \\
\text { dentro del Plan destinado a las huacas, y se tomó } \\
\text { por referencia las investigaciones ya hechas, } \\
\text { como por ejemplo la del Arq. Guzmán, que es un } \\
\text { entendido en el tema». }\end{array}$ \\
\hline
\end{tabular}

«Por supuesto que hay que aprovechar que tenemos las huacas en el campus, sería muy bonito que podamos usar las huacas como un lugar turístico para la gente del campus y también para los pobladores de Lima norte».

Fortalezas y "Yo creo que sería un gran aliciente, debilidades muy interesante que la huaca sea investigada, y ojalá que en poco tiempo se puedan hacer otros tipos de estudios, se puede aprender bastante sobre las técnicas que ellos empleaban. Se toman muchos referentes de fuera y olvidamos un poco lo nuestro. Además, la tememos en el mismo campus, es algo muy provechoso».
«Al tener la huaca UNI Cismid, se debería tener una integración, como un circuito de huacas, algo interesante que pueda vincular a los alumnos. A nive de facultades, se ha podido avanza algo, junto con la Facultad de Arquitectura, se está buscando una mayor comunicación».
«Una de las principales fortalezas es que el patrimonio prehispánico está catalogado en el Ministerio de Cultura. Además, también están la huaca UNI Cismid que tiene un arqueólogo asignado estudiando el tema. La debilidad sería que hay una cancha deportiva en la huaca UNI MINAS que ha agredido un poco los bordes, además de las obras para los nuevos reservorios de agua para la universidad. Se debe evitar el impacto negativo de estas obras, las cuales todavía se están trabajando».
Yo creo que es muy importante que, en la UNI, que es una universidad donde no se tocan las humanidades, se haga énfasis en estos temas con los estudiantes de las especialidades de Ingeniería y Arquitectura, siendo temas tan relevanEducacion pa- tes que nos hablan de nuestro pasado y trimonial que nos permiten no solo saber cómo era la vida hace cientos de años, sino también sacar provecho de los conocimientos que nuestros antepasados han dejado como legado. Ojalá que más adelante se considere en los sílabos de las diferentes especialidades».
«Hoy en día, en la educación universitaria a nivel mundial, las ingenierías se están juntando, y se tiene una visión más amplia e integra. Y la parte de las humanidades son un complemento importante, en mi opinión. Creo que la huaca UNI Cismid podría tener un uso importante para la educación y para que los alumnos la usen».
«En realidad, lo que falta un poco es, por ejemplo, cuando nos enseñan a diseñar en FAUA. Creo que nos falta la teoría, el pensar en cómo hacer las cosas, reflexionar acerca del patrimonio, conocer el verdadero significado del patrimonio; así, que yo creo que sí es importante involucrar al patrimonio en el tema de la malla y demás».
Valores patrimoniales

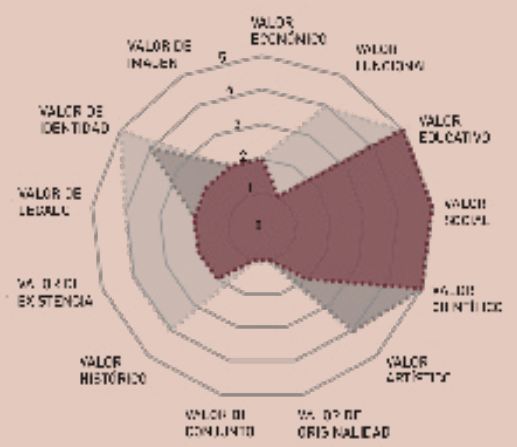

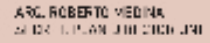

Elaboración propia sobre la base de entrevistas (citas textuales). Adaptado de la tabla de valores patrimoniales de Montañez, 2016. 


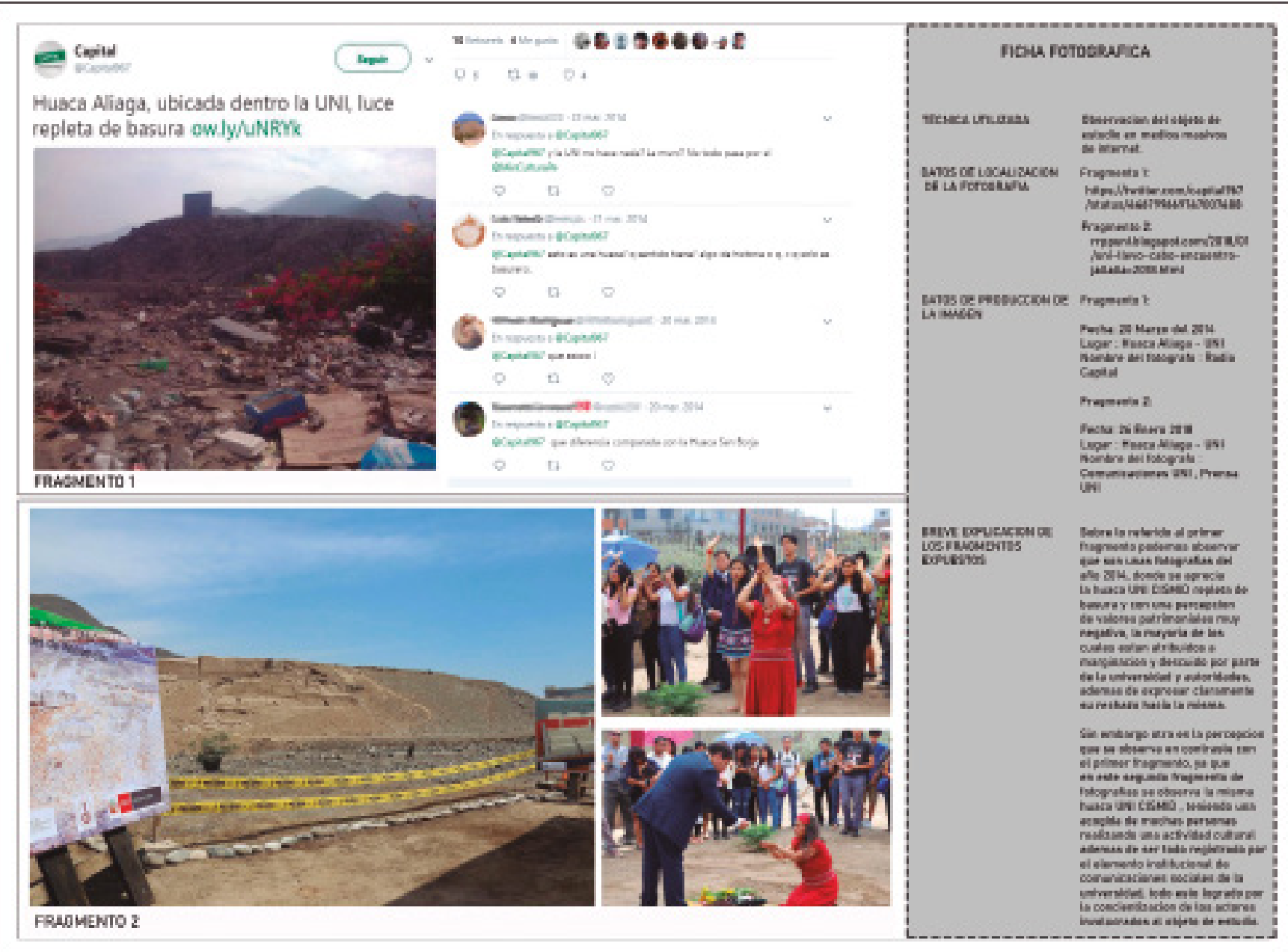

mayor interés por conocer su historia, a este primer momento se le atribuye un valor patrimonial de existencia.

Entre las cualidades manifestadas por la comunidad universitaria, la mayoría de los entrevistados manifiesta que reconoce a la huaca UNI-Cismid; sin embargo, no tiene registro de la huaca UNI-minas. Por lo que una explicación es que la huaca UNI-Cismid tiene una parte del resto arqueológico conservada y, además, está visiblemente más accesible que la otra, lo cual se entiende como un valor de existencia, mas no se reconoce un valor de conjunto, puesto que se podría decir que no se entiende el patrimonio prehispánico mientras físicamente no sea visible.

Según los resultados, se puede afirmar que uno de los valores que más se repiten en la comunidad universitaria es el valor histórico y esto se debe a que hay una conciencia parcial sobre la historia de la UNI.

A los cuestionarios referidos a qué tipo de actividades se desearía realizar en las huacas de la UNI, las respuestas que se dieron fueron variadas:

Limpiarlas y reconstruirlas, no fue una de las respuestas más concurridas, ya que si se reconoce que la huaca UNI-Cismid está limpia y con vigilancia permanente.
Figura 13. Ficha de fotografía en medios masivos de internet. Adaptado de Silva (2006), sobre la base de Metodología de trabajo. 
devenir Vol.6, N¹2, JULIO- DICIEMBRE 2019, PP. 155-178 - EstUDIOS I ISSN 2312-7562 | E-ISSN 2616-4949

UNIVERSIDAD NACIONAL DE INGENIERÍA, LIMA

doi: https://doi.org/10.21754/devenir.v6i12.748

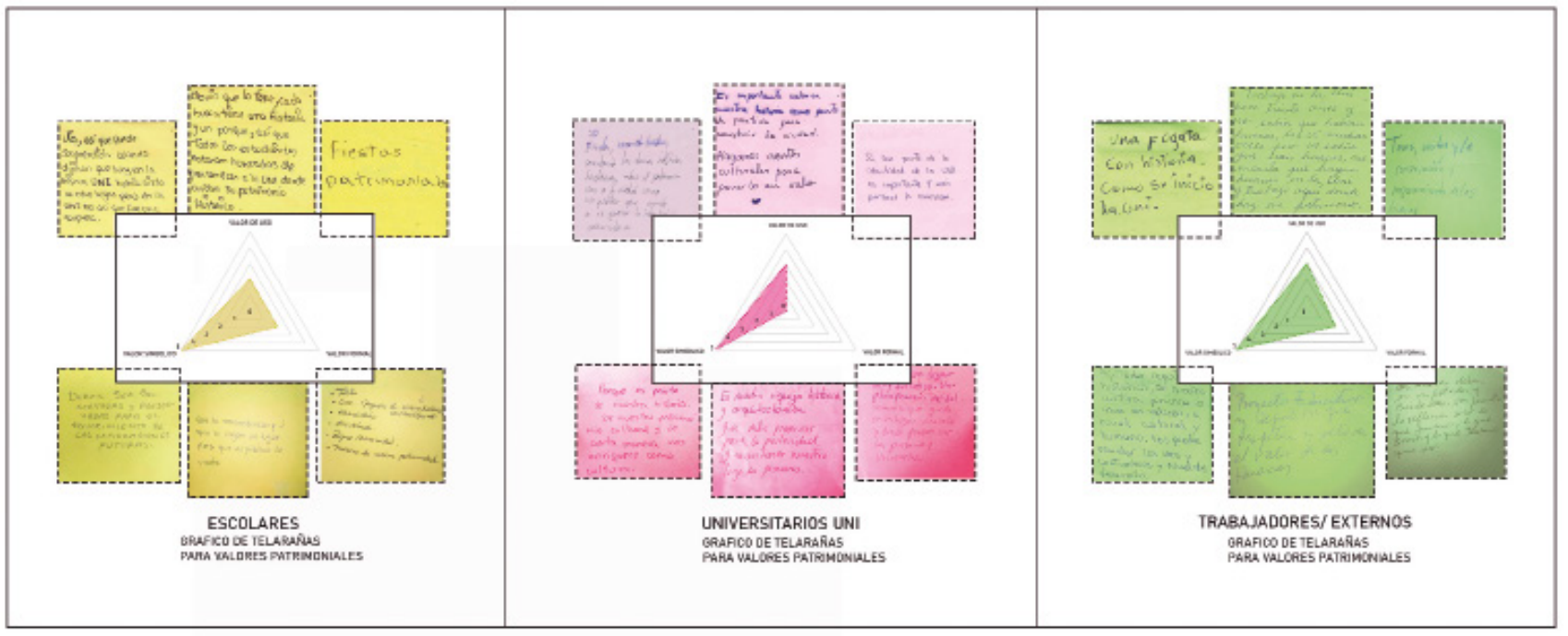

Figura 14. Gráfico de valores patrimoniales y fotografías obtenidos en la Feria Qhatuni 2018. Adaptado de «Subclasificación de valores patrimoniales para el bien inmueble», Montañez, 2016.
- Realizar visitas guiadas a las huacas de la UNI, se puede afirmar que eso sería viable ya que existen muchos casos exitosos de recorridos guiados a sitios arqueológicos. Uno de ellos y muy reciente es el caso de la PUCP, en la cual existen visitas guiadas para poder conocer el patrimonio prehispánico de la Universidad.

Con respecto a la realización de fiestas patrimoniales, o algunas festividades conocidas, también se tuvo una aceptación; sin embargo, el porcentaje no es tan alto. Esto se puede explicar en el hecho de que es mucho más sensible convivir con el patrimonio, que visitarlo en un ritual por periodos del cual muchos no son partícipes.

- Realización de un museo de sitio, también fue una de las respuestas con mayor porcentaje de aceptación, esto se puede entender como una necesidad de acompañar contemporáneamente al patrimonio prehispánico. En este caso, se considera le da al patrimonio prehispánico un valor de educativo, que se sustenta en acciones vistas anteriormente en otros casos similares, pero con una mirada muy preliminar.

Para los cuestionamientos referidos a los valores negativos atribuidos al patrimonio prehispánico de la UNI, se obtuvo que lo más preocupante para la comunidad universitaria es no saber qué es lo que hay en las huacas y no poder utilizarlas. También manifestaban que les gustaría que formen parte de los espacios públicos del campus universitario. Esto es revelador ya que nos dice que existe una intención de proximidad y una gran curiosidad, la cual puede ser utilizada positivamente para poder empezar a afianzar los lazos entre los sujetos patrimoniales y el objeto.

En relación con los expertos, se puede decir que todos reconocen al patrimonio prehispánico como una oportunidad para poder incluir al componente humanístico dentro de los planes universitarios. Para los expertos, los valores patrimoniales que más se repiten son los valores de identidad, educativos, sociales, científicos y artísticos, esto se reconoce en alguno de los gráficos antes mostrados en los resultados.

\section{La visión patrimonializadora del colectivo Jallalla}

Sobre la visión patrimonializadora del colectivo Jallalla, se puede comprender que, a pesar de ser un grupo con voluntades positivas para el encargo del patrimonio en la UNI, no llega a ser suficiente. Esto se debe a que, según lo dicho por los propios miem- 


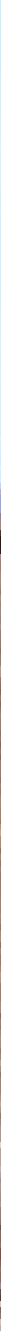

bros del grupo, la falta de una base institucional que se encargue administrativamente del patrimonio prehispánico de la UNI.

Asimismo, se puede mencionar que una de las maneras de reforzar la labor patrimonializadora del colectivo Jallalla son los grupos de investigación, ya que de esta forma se pueden sostener las acciones, y así promover la investigación del campus.

\section{Conclusiones y reflexiones finales}

En cuanto al objetivo general de este estudio, se concluye que se pudo comprender los principales valores atribuidos al patrimonio prehispánico de la UNI. Entre ellos, el valor de uso, valor histórico, valor educativo y valor de pertenencia, los cuales vinculan positivamente a la comunidad universitaria.

Cabe mencionar que las relaciones entre la universidad y su patrimonio prehispánico, actualmente, sí tienen un componente oficial, gracias a la existencia del Plan Director UNI 2018-2028, el cual considera al patrimonio prehispánico dentro de los lineamientos y su visión de campus universitario en el futuro. No obstante, se debe conocer cuáles son las principales inquietudes de la comunidad universitaria, como se realiza en este estudio, así se tendría una conciencia social de lo que sucede en la UNI y qué visión tienen sobre ella para el futuro.

Se identificó una importante aceptación por parte de los entrevistados y la comunidad universitaria sobre el tema, y se registró satisfactoriamente eventos como Jallalla, Limpia tu huaca, eventos de carácter patrimonial, etc. De tal manera que el patrimonio prehispánico de la UNI se pueda utilizar como un gran laboratorio, donde se permita a la comunidad universitaria desarrollar sus capacidades, para atender problemas reales dentro del campus universitario. A su vez, incorporar al plan curricular universitario
Figura 15. Fotografía Huaca UNI Cismid. Archivo fotográfico personal, 2018. 
devenir Vol.6, N¹2, JULIO - DICIEMBRE 2019, PP. 155-178 - EstudIOS I ISSN 2312-7562 | E-ISSN 2616-4949

UNIVERSIDAD NACIONAL DE INGENIERÍA, LIMA

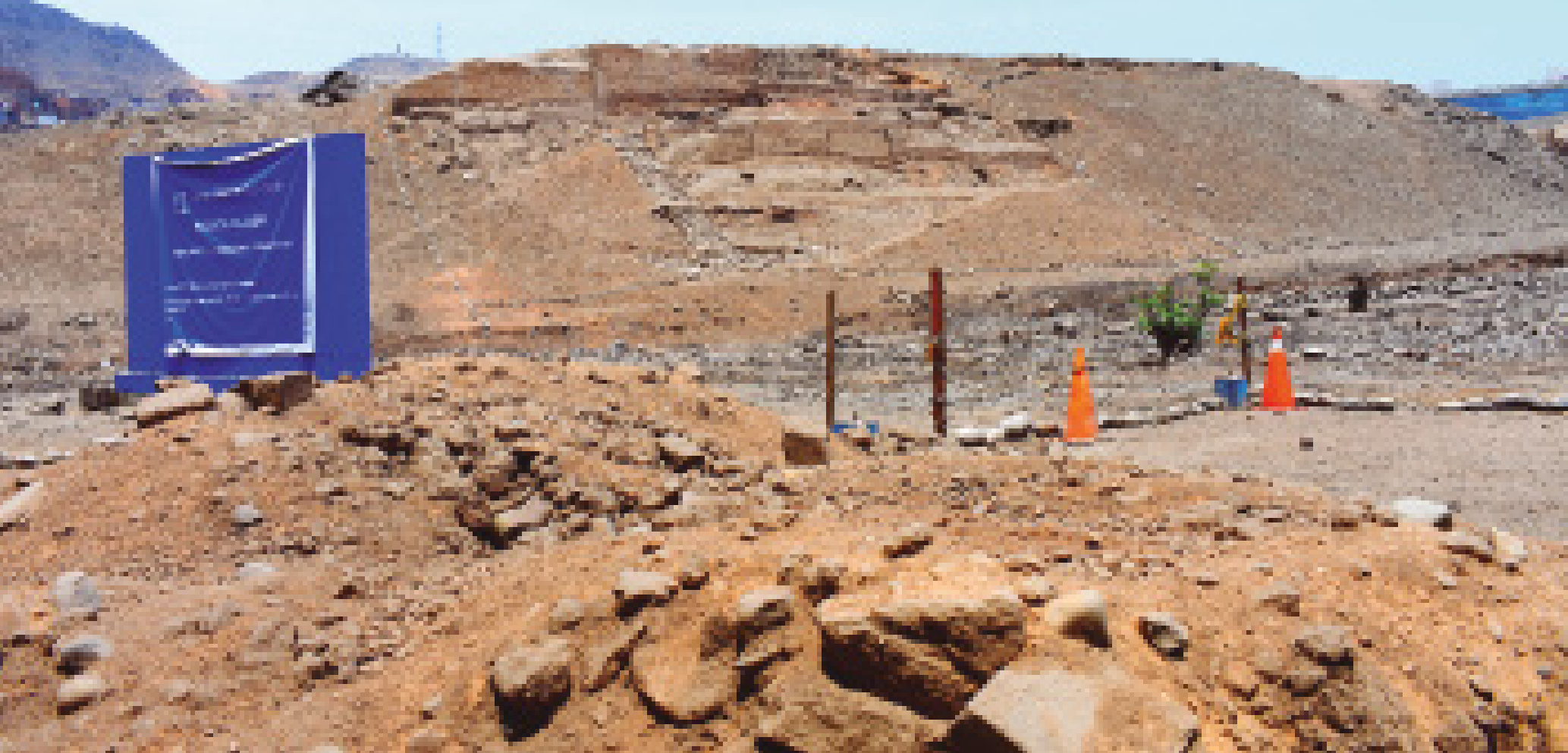

Figura 16. Fotografía Huaca UNI-Cismid tomada en octubre del 2018. Archivo fotográfico personal,

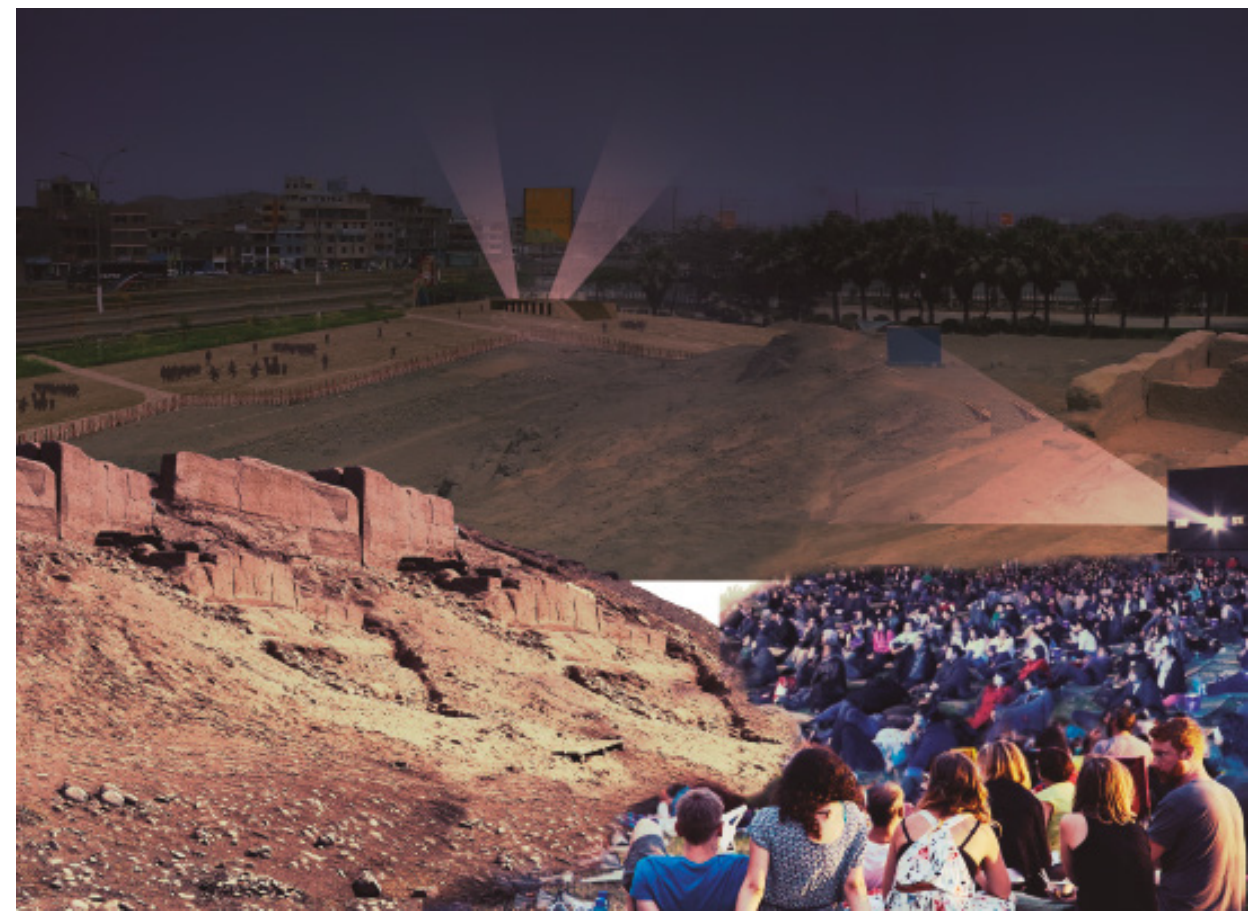

Figura 17. Collage realizado para la feria Qhatuni 2018, que interpreta los diversos usos que podría tener la huaca UNI-Cismid en su acercamiento con la comunidad universitaria. Elaborado por Eduardo Becerril Cotera, miembro del colectivo Jallalla. 


\section{iLIMPIA TU HUACA!}

\section{CAMPAÑA DE LIMPIEZA HUACA ALIAGA - CISMID}

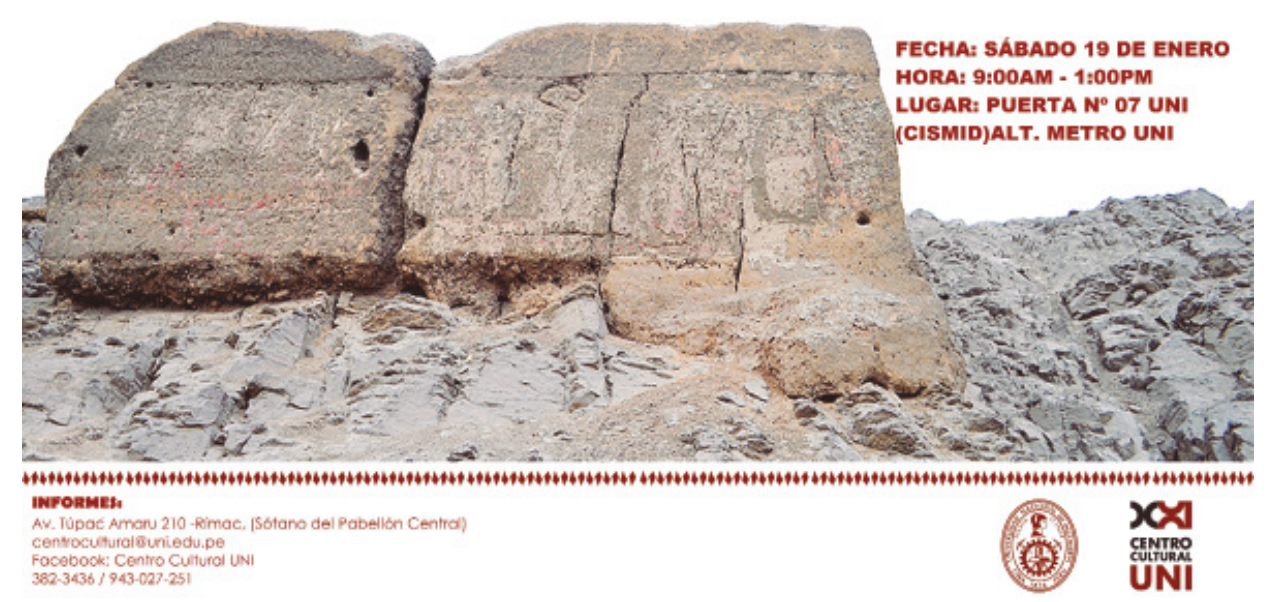

Figura 18. Afiche de Limpia tu huaca, evento realizado en pro del cuidado de las huacas de la UNI 2018. Tomado del portal web Facebook Jallalla.

temas como patrimonio, humanidades, sociología, para así no solo atender el deber científico y técnico, sino también comprender la importancia de la visión holística desde el pregrado.

Para agregar algunas reflexiones sobre la actual situación de la UNI, es importante mencionar que algunas facultades obtuvieron parte de la educación patrimonial en sus aulas, aunque de manera explícita, pero sí se dio, algunos alcances, por ejemplo, en la Facultad de Arquitectura, la Facultad de Ingeniería Ambiental; sin embargo, es necesario que se pueda tener un mayor seguimiento y se puedan lograr múltiples alcances.

Finalmente, a modo de reflexión final, se identificó los principales problemas, siendo uno de los más recurrentes en las entrevistas el tema de la institucionalidad y la visión de universidad integrada al patrimonio, en este caso en concreto, el patrimonio prehispánico. Por lo tanto, es importante generar un espacio institucional que pueda darle soporte a la gestión del patrimonio cultural dentro de la UNI, y así apoyar en los colectivos patrimonialistas, en las áreas académicas correspondientes, en promover la investigación del campus de la universidad, para tener como aliados a la comunidad universitaria, y así lograr un campus integral que pueda auto sostenerse (ver Figuras $15,16,17$ y 18$)$.

\section{Referencias}

Bringas, A. (2018). La gestión del patrimonio arqueológico de la Pontificia Universidad Católica del Perú. En Devenir. Revista de estudios sobre el patrimonio edificado, 5(10), 91-108.

Castillo de Herrera, M. (2011). La universidad: hecho urbanístico, económico y cultural frente a sus desafíos actuales. Revista Bitácora Urbano Territorial, 1(18), 93-104. 
devenir Vol.6, N¹2, JULIO-DICIEMBRE 2019, PP. 155-178 - EstUDIOS | ISSN 2312-7562 | E-ISSN 2616-4949 UnIVERSIDAD NACIONAL DE INGENIERÍA, LIMA

doi: https://doi.org/10.21754/devenir.v6i12.748

Campos Calvo-Sotelo, P. (2011). Arquitectura y universidad en la sociedad contemporánea: Innovación abierta y aprendizaje activo en las cuatro escalas espaciales. En CIAN-Revista de Historia de las Universidades, 14(2) ,149-182.

Del Castillo, J. y Sopla, P. (2018). Paisajes prehispánicos intersticiales: Naturaleza urbana y patrimonio arqueo astronómico en Ñaña, Lima. En Devenir. Revista de estudios sobre el patrimonio edificado, 5(10), 153-174.

Feliu, J. (julio-diciembre, 2014). Emergencias intelectuales. En Devenir. Revista de estudios sobre el patrimonio edificado, 1(2), 10-26.

Hernández Sampieri, R., Fernández, C., y Baptista, P. (2010). Metodología de la investigación: Roberto Hernández Sampieri, Carlos Fernández Collado y Pilar Baptista Lucio (5a. ed.). México D.F., México: McGraw-Hill.

Ibáñez, J. (1999). Vivir las ciudades históricas. Seminario. Universidad y ciudad histórica. La gestión del patrimonio. Universidad de Alcalá.

Indovina, F. (2006). Ciudad y universidad en el siglo XXI De la Torre de Marfil al Palacio de Cristal, del Palacio de Cristal a la Plaza. En Bellet C, Ganau J. (2006), Ciudad y universidad. Ciudades universitarias y campus urbanos (pp. 23-39). Lleida, España: Milenio.

Montañez, M. (julio-diciembre, 2016). Gestión y valoración del patrimonio histórico inmueble en el Centro Histórico del Callao. En Devenir. Revista de estudios sobre el patrimonio edificado, 3(6), 98-124.

Nieto, C. (2018). La apropiación social como elemento preventivo en la salvaguarda de los bienes culturales. Universidad Politècnica de Valencia.

Silva, A. (2006). Imaginarios urbanos: hacia la construcción de un urbanismo ciudadano Metodología/ Armando Silva. Bogotá: Convenio Andrés Bello, Universidad Nacional de Colombia.

Villamón, T. (2017, julio-diciembre). Reflexiones teóricas contemporáneas sobre patrimonio edificado y su significado. En Devenir. Revista de estudios sobre el patrimonio edificado, 4(8), 123-133. 